\title{
المرأة في قوانين الميراث في مصر القديمة
}

\section{Woman in inheritance laws in Ancient Egypt \\ محمد حلمي عيسي أحمد \\ مدرس مساعد - كلية الاثار - جامعة سوهاج \\ Mohamed H. Essa}

Assistant Lecturer at Faculty of Archaeology-Sohag University

m essa69@yahoo.com

(الملخص:

تميزت المرأة في مصر القديمة عن أقرانها في الحضارات القديمة الأخرى أنها كانت ندا قويا للرجل أمام القانون؛

استطاعت أن تقف بنفسها أمام الهيئات القانونية المختلفة للتقاضي وإبرام العقود والوصايا، كما أنها تمتعت بالاستقلالية القانونية عن زوجها. كذلك امنلكت جميع أنواع الممنلكات الثابت منها والمنقول، وامتلكت الحق الكامل في التصرف فئه فئها. سنبرز هذه الورقة البحثنة دورها في جزئية معينة من القانون، أي في عملية التوريث. أبرزت الوثائق القانونية والأدبية أن المرأة

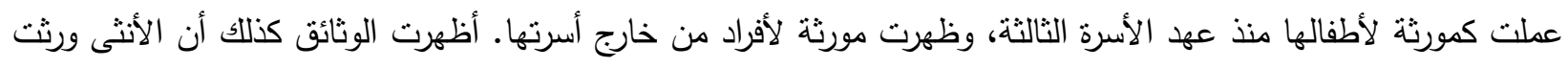

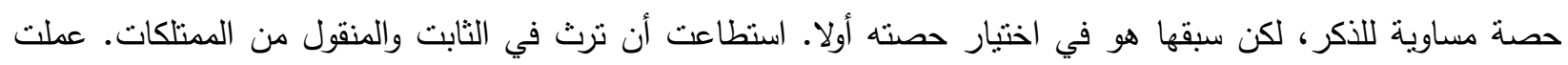

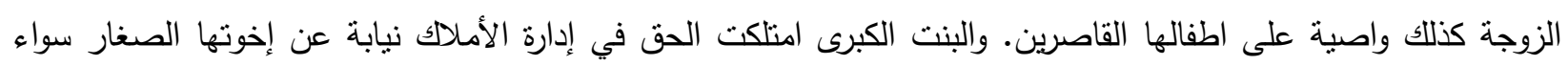

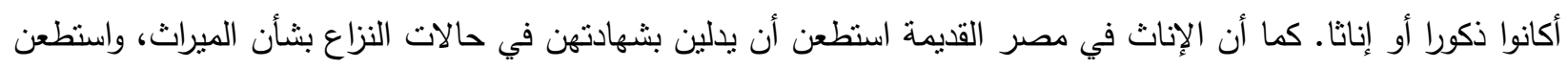

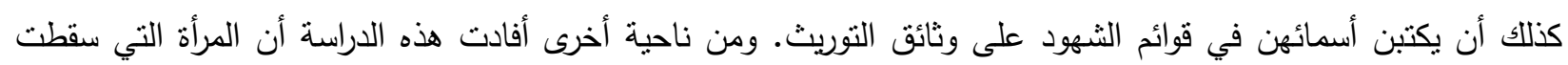

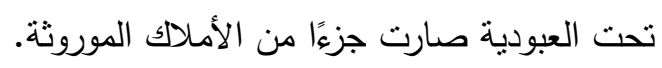

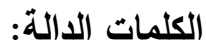
المرأة في مصر القديمة؛ عملية ميراث؛ التركة؛ القانون في مصر القديمة

\section{Abstract:}

From a law perspectiv, elite women and men were virtually equal, and they could deal with property on equal terms with men, and they were able to represent themselves in the statutory bodies for litigations and concluding the contracts and testaments. The woman in pharaonic time could possess all types of property, immovables and movables. This research paper was prepared to highlight the contribution that womenmade in the inheritance process. She was attested as a testatrix since the era of theGreat Pyramid. She worked testatrix for her children and non-blood relatives. Also, the texts display that the heiress inherited a share equal to the male heir, but he proceeded her in choosing the shares. The female inheritors in immovable and movable properties.

Furthermore, the wife acted as trustee for her minor children and seized the entire estate on their behalf . In the same vein, the eldest daughter can administrate the inheritance on behalf of the underage co-heirs, whether females or males. The women were summoned as witnesses in the disputes that arose over the inherited property. They also acted as witnesses in the last 
wills and testaments. Finally, the enslaved females were regarded as belongings of their master, he could transfer them through inheritance.

\section{Key words:}

Pharaonic woman, inheritance process, property, law succession.

كانت المرأة في مصر القديمة عامة قادرة علي ممارسة قدر معين من التأثير خارج المجال المنزلي. حيث استطاعت أن تمارس الأعمال الصناعية والتجارية بحرية كاملة. وقد عملت بالفعل في معظم المهن، على سبيل المثال: تقلدت مهنة سيدة الأعمال والمديرة، ورئيسة المخازن، ومفتشة على غرفة الطعام، ومفتشة على الخزانة، ومشرفة على الملابس، وكما تعلمت المرأة منذ عهد الدولة القديمة الطب والجراحة، وحملت لقب رئيسة الطبيبات وكانت المثال الأول في العالم للمرأة الطبيبة. وعملت المرأة كذلك في المهن الإنتاجية كصناعة الزبوت، والدهانات العطرية، وصناعة الزجاج والمجوهرات، والتحف، والأثاث، والأسلحة، وأدوات الصيد. وعملت أيضًا في أعمال الغزل والنسيج، وحياكة الملابس، والحصير، وطحن الحبوب، وصناعة العجين والخبز ، وبيع المنتجات في الأسواق.'

المرأة والرجل كانا مُتساويان أمام القانون في مصر القديمة، عكس حال أقرانهما أمام القوانين القديمة الأخرى كالقانون اليوناني والروماني. فمثناً، استطاعت المرأة المصرية أن تتقاضى أجراً مماثلاً لأجر الرجل مقابل إنجاز ذات العمل. كانت المرأة المصرية مواطنة شأنها شأن الرجل، تعيش في وطن يعترف بحقوقها كاملة؛ فكانت تستطيع أن تقاضي والديها أمام الهيئات القانونية المختلفة؛ حتى تتمكن من حماية أملاكها الخاصة. وكانت المرأة المتزوجة تتمتع باستقلال قانوني ومالي عن زوجها؛ فقد استطاعت أن تتملك في جميع أنواع الممتلكات المعروفة، الثابت منها والمنقول وكذلك العيني. وكذلك امتلكت حرية التصرف الكاملة فيها. أفادت النصوص أن المرأة في العصر الفرعوني اكتسبت هذه الممنلكات بطرق عدة، منل: الثراء والدفع مقابل إنجاز الأعمال، وكذللك حازت على أملاك عن طريق الميراث من الآباء والأخوة ومن الأزواج. يرى شفيق علام أن المجتمع المصري القديم اعترف بحقوق المرأة في ملكية الممتلكات الثابتة بدرجة كبيرة مثل الرجال، حيث إن القضايا التي دُرست حتى الآن بيَّنت بوضوح أن النساء من مختلف طبقات المجتمع انتفعن بهذه الحقوق. وأظهرت بردية ويلبر (Wilbour papyrus) أن النساء في مصر القديمة

يجدر بي تقديم جزيل الثكر والامتتان لقطاع الثئون الثقافية والبعثات - الإدارة المركزية للبعثات (الحكومة المصرية) نظير منحي بعثة علمية لدراسة مشروع الدكتوراه في جامعة توبنجن بألمانيا، وكذلك للأستاذ الدكتور شفيق علثئ علام، أستاذ الآثار المصرية بجامعة نوبنجن ألمانبا لإتاحة الفرصة لدراسة الدكتوراه تحت إثرافه. وكل الثكر والتقدير للزميل الدكتور أحمد كمال

$$
\text { (جامعة سوهاج) لمراجعة البحث لغويا. }
$$

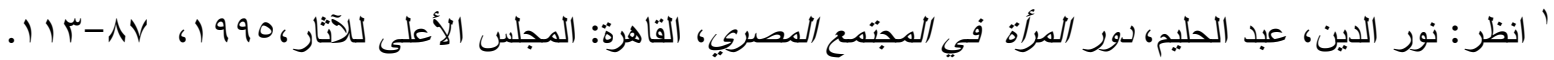
${ }^{2}$ WATTERSON, B., Women in Ancient Egypt, New York, 1991, 23 ff. 
خضعن للضرائب فيما يتعلق بممتلكاتهن من الأراضيّّ. ودلل علام أيضًا على أن النساء كان بإمكانهن نقل سندات الملكية للممتلكات الثابتة، وتصرفن فيها بعدة وسائل كالبيع والتبني واتفاقيات الميراث. وذكر أيضًا أن النساء حصلن على هذه الحقوق عن طريق ممارسات الميراث أو من خلال بعض التعهدات من جانب عائلاتهم مباشرة، من خلا المهر والوصايا وما شابه. ونظرًا لضآلة المادة العلمية المتوفرة عن نساء الطبقة الدنيا في المجتمع، نعتمد في استتناجاتتا على النصوص التي تخص السيدات البارزات في المجتمع. فمثلاً

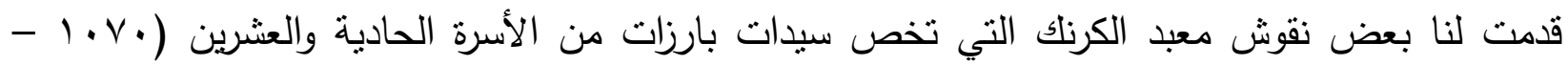
هـ 9 ق.م.) دليلاً على أن هناك امرأنين (أم وابنتها) حصلتا على حقوق ومنازل عن طريق الشراء. وهذا البحث سوف يلقى الضوء على أحد إسهامات المرأة في أحد جوانب الحياة القانونية في مصر القديمة، وهو دورها في عملية الميراث. استتادا على فحص وتحليل با نصًا يعالج أمور التوريث في مصر القديمة. كُتبت هذه النصوص على مصادر مختلفة كجدران المقابر ولوحات وبرديات وأوستراكا وغيرها، حيث خرجت تلأك المصادر من مواقع أثرية متتوعة، وهي تتحصر زمنياً فيما بين الأسرة الثالثةْ حتى الأسرة السابعة والعشرين وقد وفرت لنا تللك النصوص مادة علمية كافية لرسم هذا الدور الذي لعبته النساء في ذلك الوقت بشكل جلي.

و للميراث أركان ثلاثةث؛؛ وهي: المورث، والوارث، والموروث. المورِّث: هو الميت الذي ترك مالاً أو حقاً. والوارث: هو الذي يستحق الإرث بسبب من أسبابه الآتية، وإن لم يأخذها بالفعل لمانع، فهو مستحق الإرث من غيره لقرابة حقيقية أو حكمية. الموروث: هو التركة، ويسمى أيضًا ميراثًا وإرثًا، وهو ما يتركه

3 GARDINER, A., The Wilbour Papyrus, vol. II commentary, Oxford, 1948.

${ }^{4}$ AllaM, S., Women as Owners of Immovables in Pharaonic Egypt, BARBARA S. LESKO (ed.), Women's Earliest Records: from Ancient Egypt and Western Asia; Atlanta, 1989, $134 \mathrm{f}$.

• أقدم هذا النصوص تتمثل في نقش منت، وهو لمسئول مصري رفيع المستوى عاث فيما بين الأسرة الثالثة والرابعة. تكمن :هن أهمية هذا النص في أنه يتضمن أقدم نص سيرته ذاتية وصلنا من مصر القديمة، له قيمة خاصة لأنه يكثف الجغرافيا ومدن الثمال في ذلك الوقت المبكر من التاريخ المصري القديم. يحكى منن في سيرته تدرجه في المناصب الإدارية من كاتب إلى مشرف على كثثر من المدن. إضافة إلى كل هذا فهو يعد أول نص يتحدث عن أمور التوريث.

WILKINSON, T.A., Early Dynastic Egypt, London/New York 2001, 93, 122, 125-147;

BREASTED, J.H., Ancient Records of Egypt, Vol. I, Chicago, 1906, \&170 ff.

" أحدث هذه النصوص هو نص ديموطيقى ينتمي إلى السيدة تاسنتحور من عهد الملك داريوس الأول. وهو يعالج وصيتها التي أبرمتها من أجل ابنها الأكبر وبنتها.

Pestman, P. W, Les Papyrus dDémotiques de Tsenhor, vol.2, 1994, 57 ff. PLS. 7, 7a.

ثم معالجة هذه النصوص في مشروع الدكتوراه الذي يتم دراسته بجامعة توبنجن (ألمانيا) والذي عنون بـ "مساهمات في قانون

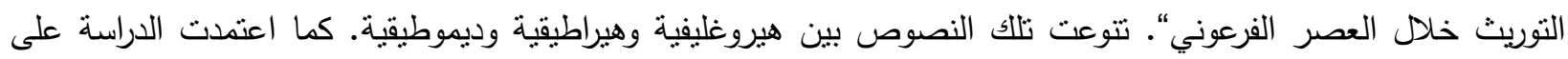

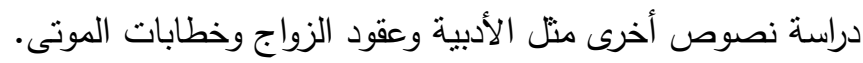

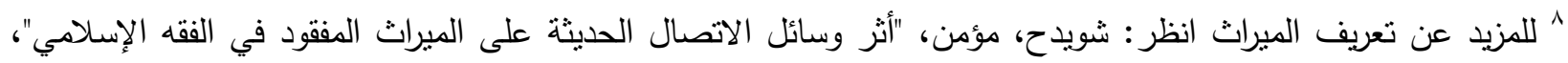

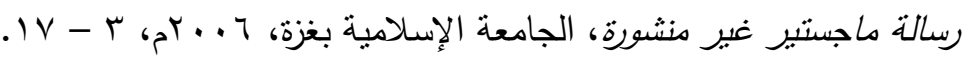


المورث من المال، أو الحقوق التي يمكن إرثها عنه. فإذا فقد ركن من هذه الأركان انتفى الإرث؛ لأن الإرث

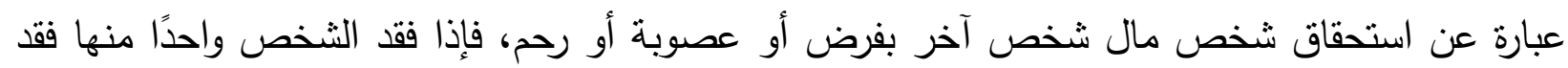
الإرث. وهناك دور ثانوي في عملية الميراث وهو دور الوصي، الذى قد يظهر في بعض عمليات الميراث

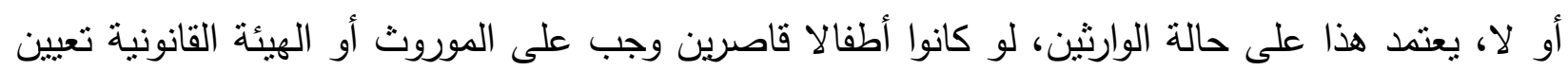

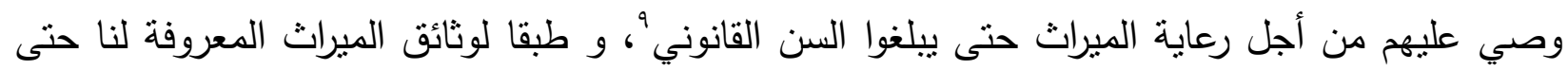

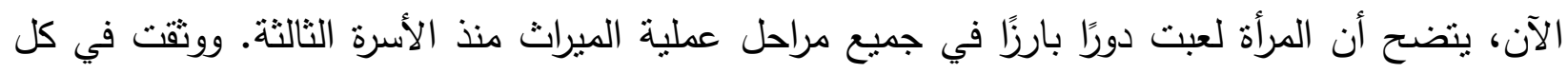

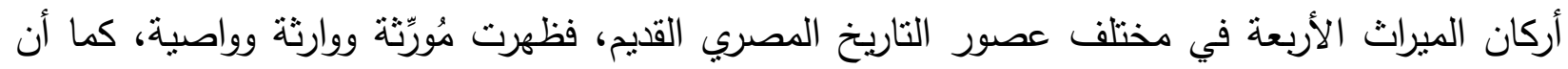
الإناث الواقعات تحت نير العبودية كنَّ جزءا من التركة الموروثة. فيما يلي ستعالج الدراسة كل مما ذكرُ فرّن مرحلة علي حدة:

\section{1المرأة كصاحبة أملاك ومورثة:}

امتلكت المرأة المصرية الحق المُطلق في التصرف في أملاكها الخاصة في العصر الفرعوني. وفقًا لقواعد الميراث المتبعة آن ذللك،إذ لم يكن يحق للزوج والزوجة أن يرث كل منهما من الآخر • واحتفظ كل

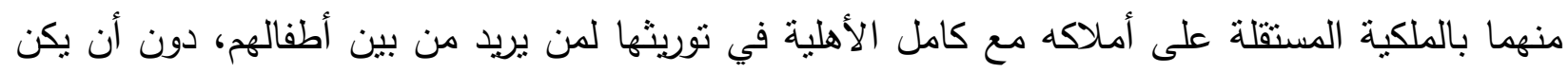

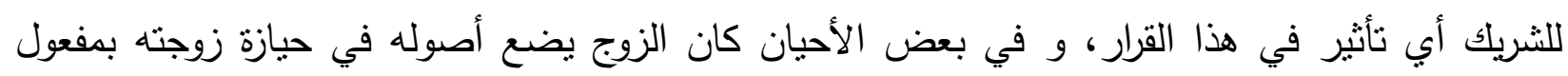
تصرف وصائي، وكان يعطي لها مطلق الحرية في نقل هذه الأصول لمن نريد من أطفالهما. '

وفقا للنصوص المتاحة، ظهرت المرأة كمورثة قبيل عصر بناة الأهرام. نص السيرة الذاتية الخاص

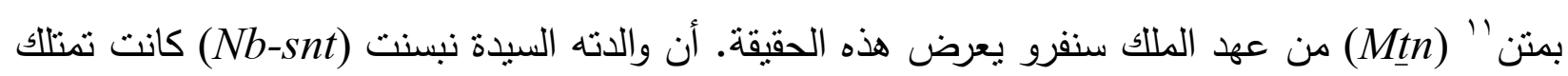

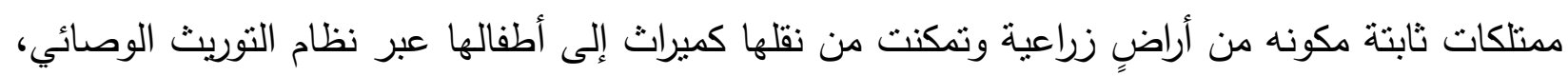

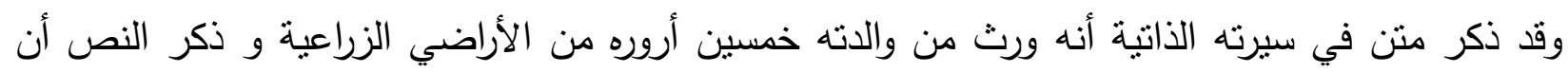

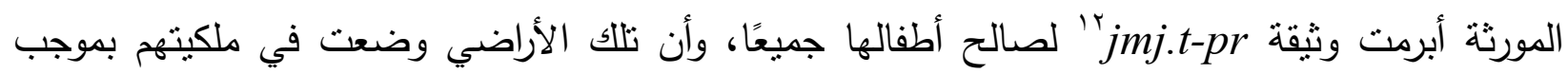

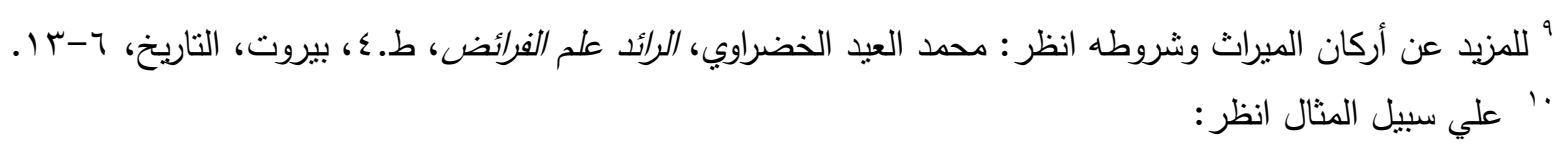

JANSSEN J. \& PESTMAN, P. W:.«Burial and Inheritance in the Community of the Necropolis Workmen at Thebes», Pap. Bulaq X and O. Petrie 16, JESHO 11, 1968, 164 f.; ALLAM, S., Papyrus Turin 2021 Another Adoption Extraordinary, CANNUYER C. \& KRUCHTEN J. (eds), Individu, Societe et Spiritualite. Melanges Théodoridès, Brusseles: Illustra, 1993, 24.; ČERNÝ :« The Will of Naunakhte and the Related Documents», JEA 31, 1945, 49.

11 GOEDICKE, H:.«Laufbahn des MTn», MDAIK 19, 1966, 66 ff. PL. 5.

rا ل ايزال علماء المصريات في حيرة من أمرهم بشأن الطبيعة الأساسية لهذه الوثيقة، حيث نم تفسير هذا المصطلح بطرق مختلفة. للمزيد عن هذه الوثيقة انظر :

LOGAN, T.:《 The imyt-pr Document: Form, Function and Significance», JARCE 37, $49 \mathrm{f}$.

AlLEN, J. P., Middle Egyptian: An Introduction to the Language and Cultures of the Hieroglyphs, Cambridge University Press, 2000, 90. 


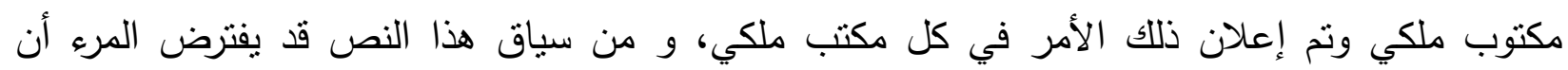

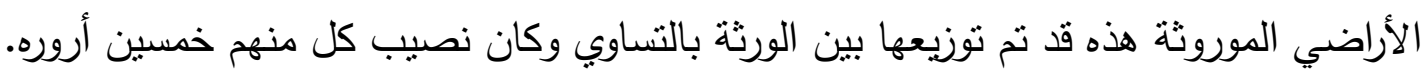

لم تصلنا أمثلة أخرى من عصر الدولة القديمة، ثُيين صراحة أن المرأة عملت كمورثة، بل نجد فقط

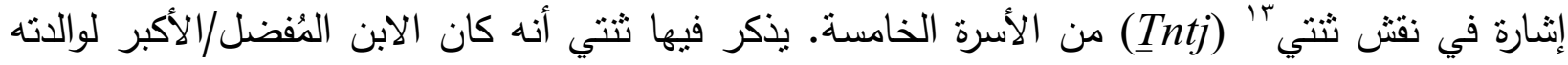

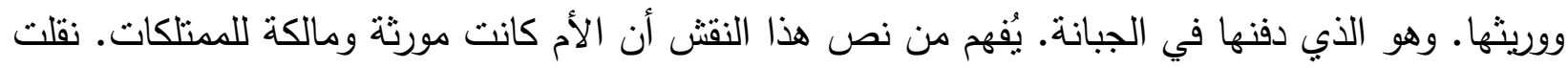

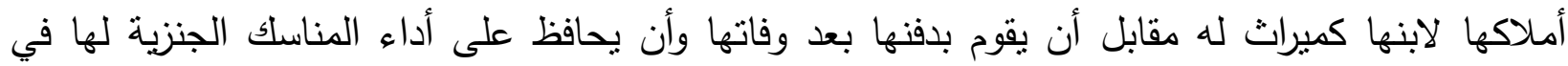
المستقبل، كما نجد أن ثتي في هذا النقش أوصى ورثته بأن يواصلوا أداء المناسك الجنزية لها من بعده. حتى الآن، لم نعرف كذلك أمثلة صريحة من الدولة الوسطى تنين المرأة مورثة، لكن هناك إنشارة لذلك

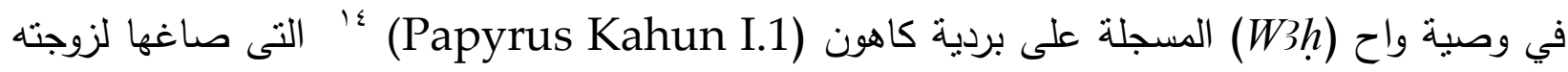

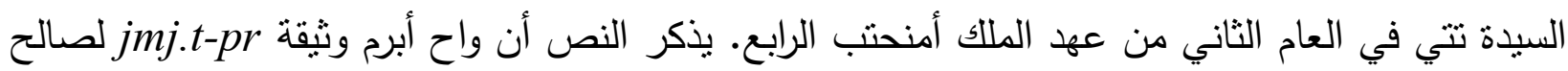

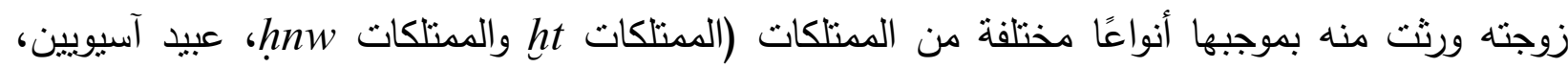
ومنازل

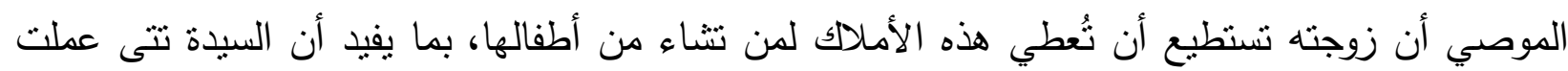

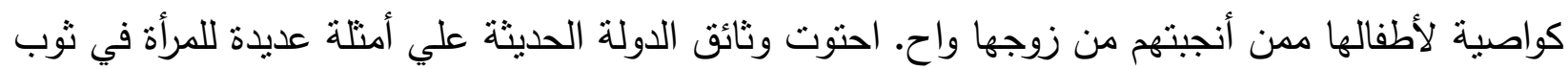
المورِّة؛ يخبرنا نص أوستراكا بتريه' (Ostracon Petrie 16) من الأسرة العشرين مثالين للمرأة المورثة.

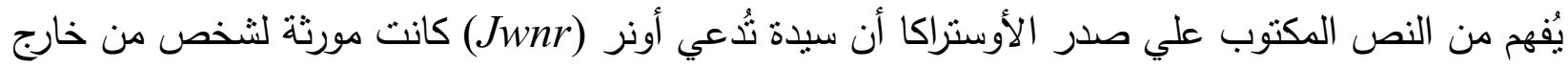

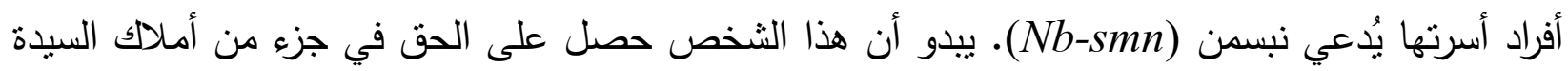

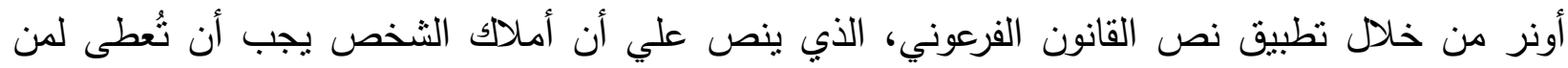

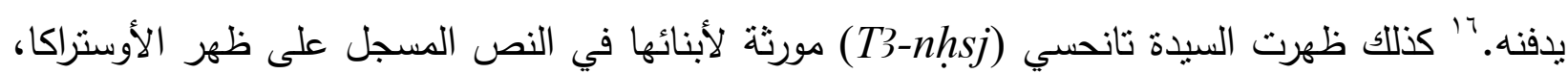
كان من بينهم شخص يُدعي ساواجيت (S3-W3

13 Moret, A., Une Nouvelle Disposition Testamentaire de l'Ancien Empire Égyptien, C.R. de l'Acad.des Inscr, 1914, 529 ff.; GoediCKE, H., Die Privaten Rechtsinschriften aus dem Alten Reich, Notring, 1970, PL. 13.

${ }^{14}$ GANLeY, A :.« The Legal Deeds of Transfer from "Kahun" Part One» , DE 55, 2003, 24, FIG. 2; ColLIER, M. \& QUIRKE, S., The UCL Lahun Papyri: Religious, Literary, Legal, Mathematical and Medical, Oxford, 2004, $104 \mathrm{f}$.

15 ČERNÝ, J., \& GARDINER, A., Hieratic Ostraca, Oxford, 1957, PLS. 21.1, 21A.1; JANSSEN

\& PESTMAn, Burial and Inheritance in the Community of the Necropolis Workmen at Thebes (Pap. Bulaq $X$ and O. Petrie 16,, $153 \mathrm{ff}$.

$$
14 \text { لأمتلة أخرى لهذا القانون في النصوص المصرية؛ انظر : بردية بولاق رقم . }
$$

Allam, S., Hieratische Ostraka und Papyri aus der Ramessidenzeit, Tübingen, 1973, 289 ff. no. 268.

ونص إناء اكسفورد

GARDiner, A., \& SeTHE, K., Egyptian Letters to the Dead mainly from the Old and Middle Kingdom, 1928, PL. 9. 
قام بتتفيذ منصوص القانون الفرعوني السابق. عندما قام بمفرده دون أية مساعدة من أشقائه بدفن والدته، بنفس المنوال، كثفت بردية بولاق' (Papyrus Bulaq 10) من الأسرة العشرين، أن السيدة تاجميت كانت مورثة لجميع أطفالها، لكن ميراثها آل برمته فقط لابنها حوي (T3gmyt) أبويه وزودهما بالأثاث الجنزي اللازم لعملية الدفن دون أية مساعدة من أثقائه الآخرين.هنالك برديتان من الأسرة العثرين تلقى مزيدًا من الضوء على الصلاحيات التى اكتسبتها النساء المورثات في العصر الفرعوني. هاتان البرديتان موجودتان حاليا في متحف الاشموليان. الأولى تُعرف بأرشيف السيدة ناونخت الذي يحتوى على وصيتها التي أبرمتها من أجل أطفالها، و وصبتها هذه كانت عبارة عن وثيقة تُعرف باسم "h3ry" يُستتبط من نص هذه البردية أن المرأة استطاعت أن تقف شخصيًا أمام القضاة بشأن ممتلكاتها الخاصة، وأن تبرم الوصايا وتسجلها، كما أنها استطاعت أن تقصر أملاكها الخاصة على بعض من أطفالها وتحرم البعض الآخر، مثلها كمثل الرجل تمامًا، كما نجد أن السيدة ناونخت في هذا النص كانت مورثة لأطفالها الثمانية ذكورًا وإناثًا، الذين أنجبتهم من زوجها الثاني. وفي وصيتها، فرَّقت ناونخت بين أملاكها الخاصة وأملاك زوجها الثاني، واشترطت أن يحصل خمسة فقط من أطفالها على أملاكها؛ وذلك لأنهم قدَّموا لها الرعاية في شيخوختها. وحَرَت الأطفال الثناثة الآخرين أن يحصلوا علي أي شيء من أملاكها؛ لأنهم كانوا عاقين بها، بل إنهم يمتلكون الحق في أن يرثوا فقط في أملاك والدتهم: "قالت: أما عني فأنا (امرأة) حرة من أرض الفرعون. لقد ربيت الخدم الثمانية الخاصة بكم، ولقد أعطيتهم الأثاث المكون من كل الأشياء، التي

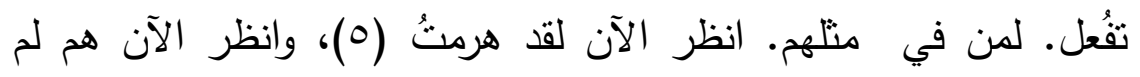
ينفذوا احتياجاتي، أما بخصوص كل من وضع بده في يدي منهم، أنا

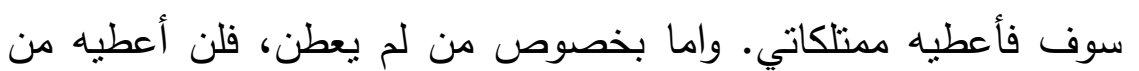
ممنتكاتي"

.(' ${ }^{\wedge}$ pAshmol. Mus. 1945.97: doc. II col. I)

والبردية الثانية تُعرف ببردية التبني الاستثنائي '، وهي تفرد لنا مزبدًا من التفاصيل حول وضع النساء اللائي عملن كمورثات، و يبين هذا النص أن قدرة المرأة لم تقتصر علي توريث الممنلكات فقط، سواء كان ذلك النقل عبر البنود العرفية للميراث أو من خلال نظام التوريث الوصائي، بل امتلكت امنيازات أخرى،

17 JANSSEN \& PESTMAN:Burial and Inheritance in the Community of the Necropolis Workmen at Thebes (Pap. Bulaq X and O. Petrie 16)», 137 ff. PLS. 1-2.

18 ČERNÝ, J., The Will of Naunakhte and the Related Documents, 29 ff. PLS. 8-9.

19 هذه البردية من ذات مصدر ريفي من مدينة سبرو مرو التي تقع جنوب هيراكليوبوليس ماجنا. البردية في الأصل دفنت علي بعد •ع قدمًا تحت الأرض من أجل الحفاظ عليها. GARDINER, A.:«Adoption Extraordinary» , JEA 26, 1940, 23. 
فعلي سبيل المثال، نجد أن السيدة رن-نفر (Rn-nfr) قامت بتحرير العبيد وجعلهم أطفالاً لها عن طريق التبنّي، ومن ثم قامت بترسيمه ورثة شرعيين لها. وعلاوة علي ذلك، استطاعت تبني شقيقها الأصغر وتأسيسه واحدًا من ورثتها أيضًا ('pAshmol. Mus. 1945.96). وتُضيف لنا اوستراكا Ostracon Gardiner 90 من عصر الرعامسة أنه من ضمن المميزات التي اكتنبتها المرأة المورثة، أنها استطاعت أن تمنلك ممتلكات مكونة من "أيام عمل العبيد"بr داخل المدينة وخارجها، وكما واستطاعت أيضًا أن تورثهم لابنها، المدعو قني (Qnj)،وقد ذكر النص أسماء هؤلاء العبيد حيث كان عددهم سبعة أشخاص ذكورا وإناثا. كما أن أحد هؤلاء العبيد كان لديه أطفال.

يكثف نقش علي لوحة من الحجر الجيري من الأسرة الثانية والعشرين، تُعرف باسم لوحة الداخلة بَ، وهي تُلقي الضوء علي منطقة الواحات، تتحدث عن ملكية امرأة عاشت خلال حكم الأسرة الليبية المتمصرة في بداية الألفية الأولى قبل الميلاد، يُفهم من النص أن هذه المرأة كانت صاحبة أملاك ثابته مكونة من مجموعة آبار ري وكذلك الأراضي الزراعية التي تحيط بها. نظرًا للتغيرات الجغرافية التي طرأت علي المنطقة فقد حدثت تغييرات في مخطوط نلك الأراضي؛ مما جعل هذا الوربث يلجأ إلى السلطة القضائية لتأكيد ملكيته لهذه الأبيار والأراضي. وبعد فحص السجلات الرسمية للدولة تم التأكُّد من أن نلك الأراضي كانت مُسجلة

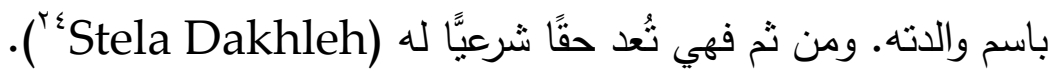
كشفت النصوص الديموطيقية من الأسرة السابعة والعشرين أن المرأة عمت مورثة لأطفالها وأبرمت لهم الوصايا بشأن الميراث، فعلي سبيل المثال كتبث السيدة تاسنتحور (T3-snt-n-Hr) وصيتها لصالح ابنها بادي-أمون-حتب (Pw-dj-Jmn-htp) ولابنتها رورو (Rww) و اشترطت فيها أن تركتها الخاصة سوف تُقسم مناصفة بينهما، علاوة على ذلك وضعت شرطًا مستقبليَّا في وصيتها بشأن أي طفل آخر سوف تتجبه مستقبلاً، بأن يُخرج له كلاً من بادي-أمون-حتب ورورو حصة له من هذا المبراث، و الواضح أن الأم

20 GARDINER,:Adoption Extraordinary, 23 ff. PLS. 5a-7.; AllAM, S., :.«A New Look at the Adoption Papyrus (Reconsidered)», JEA 76, 1990, 189 ff.

${ }_{21}$ ČERnÝ \& GARDINER, Hieratic Ostraca, PLS. 51. 2, 51A. 2; AlLAM, Hieratische Ostraka und Papyri aus der Ramessidenzeit, 168 f. no.165.

$$
\text { : للمزيد عن نقل أيام عمل العبيد انظر }
$$

ALLAM, S .:«Ein Erbstreit um Sklaven (Papyrus BM 10568)», ZÄS 128, 2001, 89 ff.

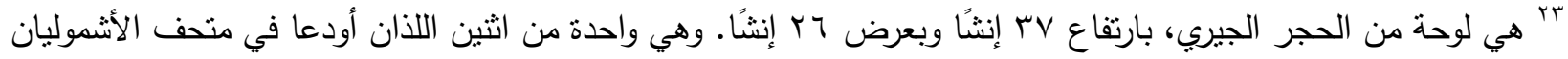

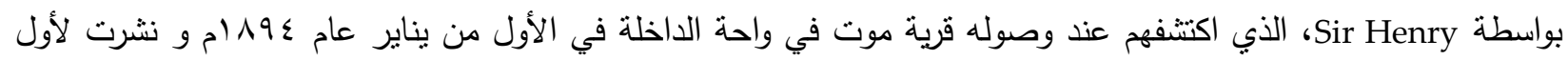
مرة في عام 999 ام على بد Spiegelberg. وهي تقدم لنا معلومات عن الظروف الطبيعية والإدارية والطبوغرافية والدينية للواحات في عصر الأسرة الثانية والعشرين من الحكام الليبيين.

GARDINER, A :.«The Dakhleh Stela», JEA 19, 1933, 19.

${ }^{24}$ GARDINER, A :.«The Dakhleh Stela», 19 ff. PLS. 5-7.; RITNER, R.K., The Libyan Anarchy: Inscriptions from Egypt's Third Intermediate Period, Atlanta, 2009, $173 \mathrm{ff}$. 
هapyri Bibl. Nat ( هاغا صاغت وصيتها خلال حياتها علي أساس أن ينم تتفيذ منصوصها بعد وفاتها . (ro 216 and Bibl. Nat 217

من خلال الأمتلة المسردة عاليًا، يمكن للمري أن يستتتج أن المرأة تمتعت بامتيازات بصفتها مورثة ومنها: • القدرة علي صك العديد من وثائق الميراث مثل وثيقة h3ry.t-pry ووثثيقة • تعيين ورثة لها سواء من خلال التبني أو من خلال القانون الفرعوني سواء من أسرتها أو من خارجها.

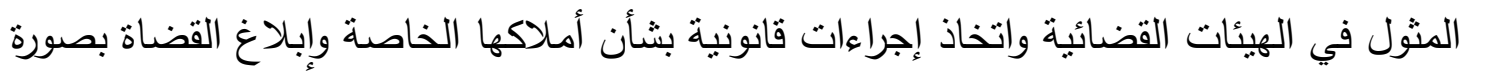
شخصية بالدوافع من وراء تمييز بعض من ورثثها عن البعض الآخر . م تحرير العبيد وترسيمه كورثة. القدرة على حرمان بعض أطفالها من ممتلكاتها الخاصة.

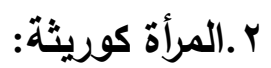

نصت إحدى مواد مخطوط هيرموبوليس (الأشمونين) القانوني بr على أن ممنلكات المورث يجب أن

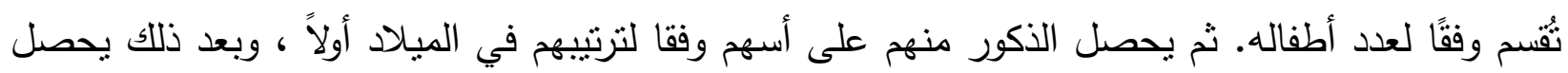
الإناث على نصيبهن وفقًا لترتيبهن في الميلاد أيضًا:

"ومن ثم ستقسم الممتلكات المتبقية إلى حصص طبقا لعدد أطفاله؛ وبعد

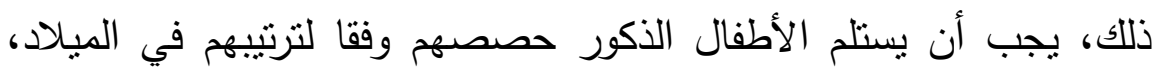

وبعدهم، يجب أن يستلم الأطفال الإناث (أنصبتهن) طبقال لترتيبهم في الميلاد

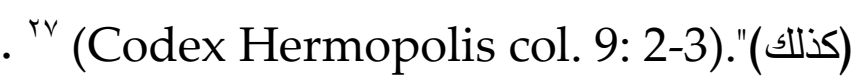

هذا يعني أن الإناث في مصر القديمة حصلن على نصيبهن من الميراث بعد الذكور .و أفادت وثائق

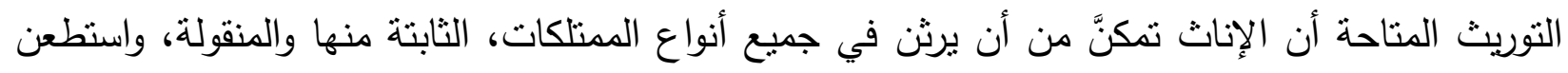

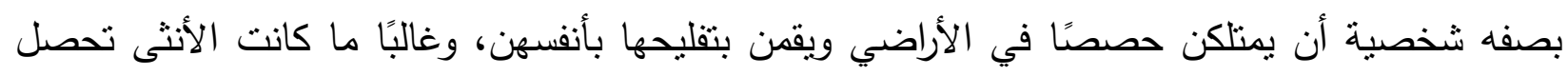

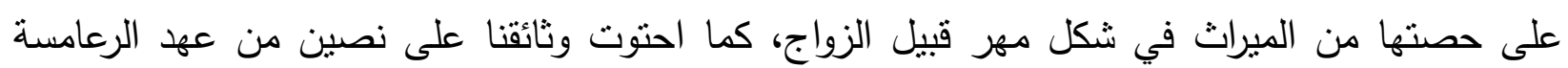

${ }_{25}$ CRUZ-Uribe, E :.«A Transfer of Property during the Reign of Darius I», Enchoria 9, 1979, 33 ff. PL. 8.; Pestman, P.W, Les Papyrus Démotiques de Tsenhor, I, 53 ff. no 5, II, PL. 6, 6a.

צr تم العثور عل مخطوط هيرموبوليس الديموطيقى بواسطة سامى جبرة في مدينة هيرموبوليس القديمة وهو حاليًا في متحف

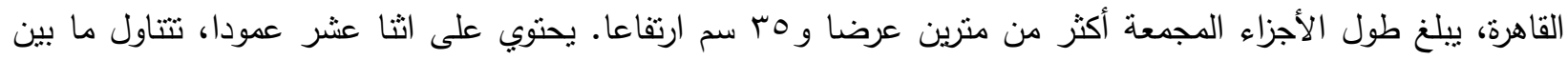

$$
\text { أمور قانونية وأخرى نظام التوريث العرفى. انظر : }
$$

Mattha, G. \& Hughes, G.R, The Demotic Legal Code of Hermopolis West, Cairo, 1997, 39 f., PLS. 14-17.

${ }^{27}$ Mattha \& Hughes, The Demotic Legal Code of Hermopolis West, 39; DOnKER VAn HeEL, K., The legal Manual of Hermopolis: [P. Mattha], Text and Translation, Leiden, 1991, 97. 


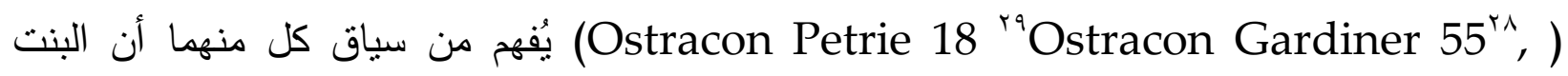
حصلت على نصيبها من ميراث والدها في وقت زفافها وذهبت به إلي منزل زوجها، وفي حالة إنهاء الزواج

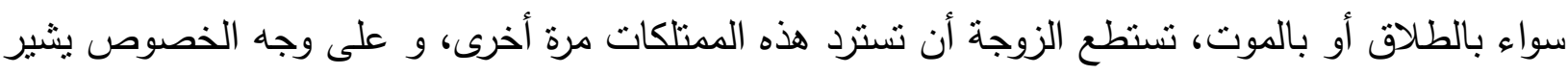

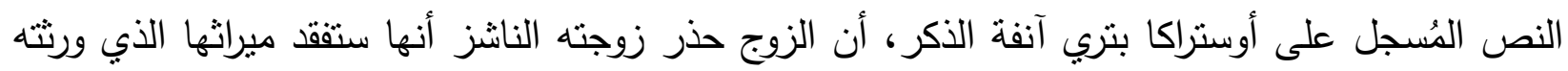

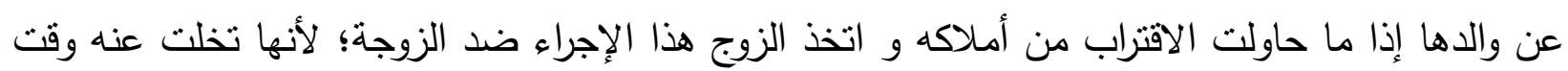

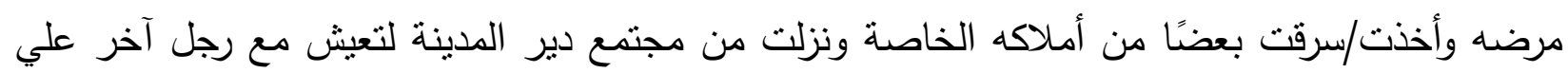
ضفاف النيل.

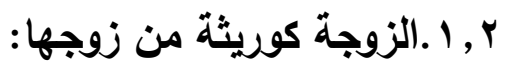

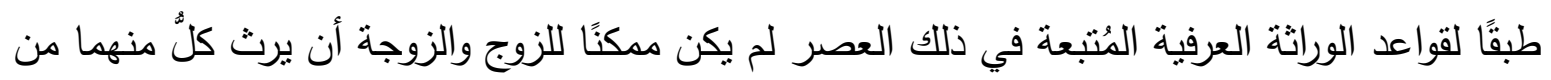

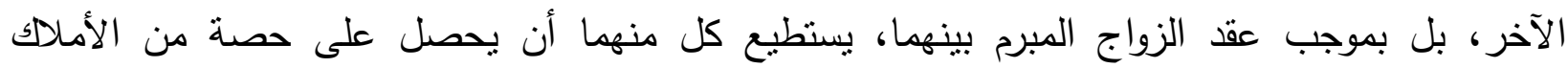

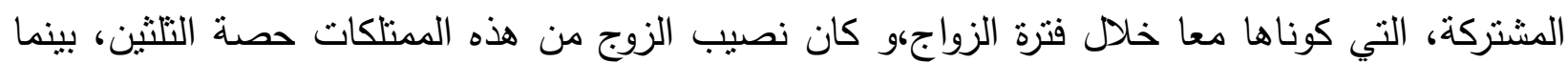

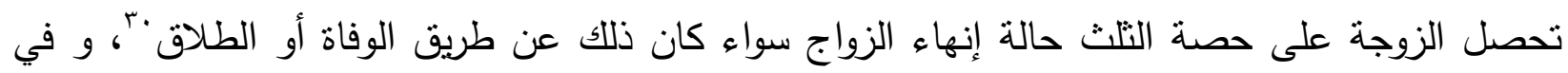

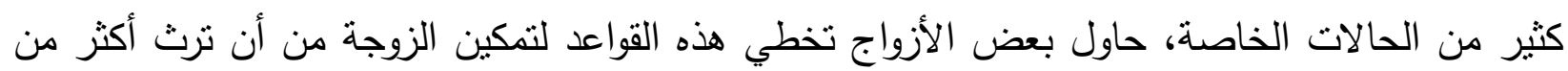

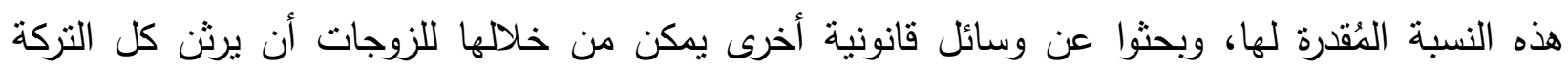

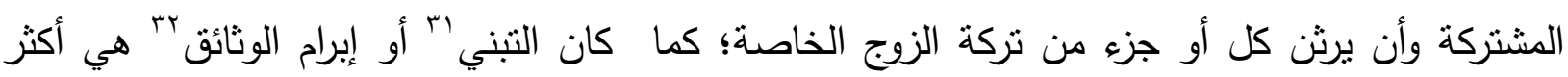

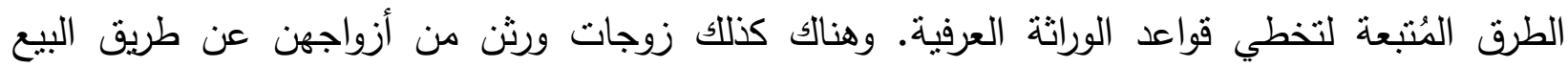
الصوري. الطرق

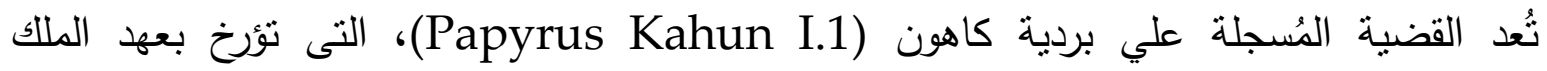
امنمتب الثالث، أقدم مثال معروف لنا يتحدث عن الزوجة التي ورثت من زوجها بنظام التوريث الوصائي.

28 ČERNÝ \& GARDINER, Hieratic Ostraca, 19, PLS. 66. 2, 66A. 2 (verso) PL. 115, 1 (recto); ČERNÝ, J. \& PEET, E.:«A Marriage Settlement of the Twentieth Dynasty», An Unpublished Document from Turin1, JEA 13, 1927, $38 \mathrm{f}$.

29 ČERNY \& GARDINER, Hieratic Ostraca, PLS. 70. 1, 70A. 1.; KRI VI, 1983, 430 f.; KRITA VI, 2012, 332 f.; ALLAM, Hieratische Ostraka und Papyri aus der Ramessidenzeit, $234 \mathrm{f}$.

30 ALLAM, Papyrus Turin , place of publication, 2021, 24; PESTMAN, P., The Law of Succession in Ancient Egypt, Leiden, Brill, 1969, $71 \mathrm{ff}$.

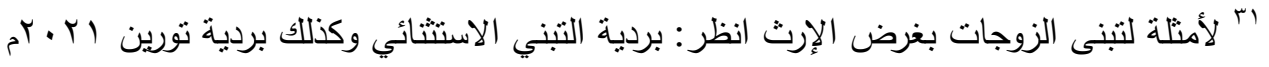

GARDINER, Adoption Extraordinary, , $23 \mathrm{ff}$.

Allam, Papyrus Turin, 24.

Papyrus Kahun I.1 انظر بردية كاهون

COLLIER \& QUIRKE, The UCL Lahun Papyri, $104 \mathrm{f}$. 
أبرم واح (W3h) وثيقة jmj.t-pr لصالح زوجته السيدة تتي (Ttj)، ورثت منه بموجبها أنواعًا عدة من

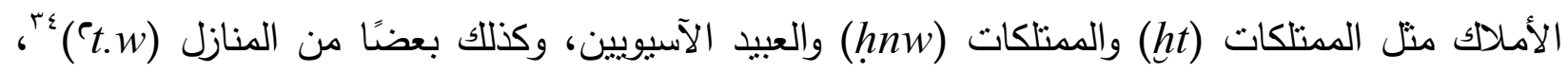
كما أن واح أعطى لزوجته الحق بأن ثُفن في مقبرته، وهناك إنثارة أخرى في بردية أخرى من منطقة كاهون

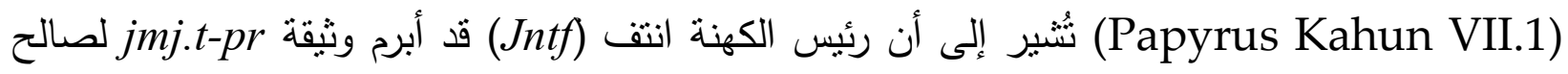

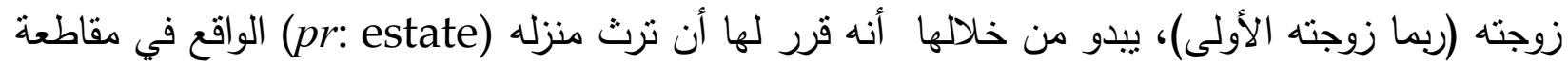

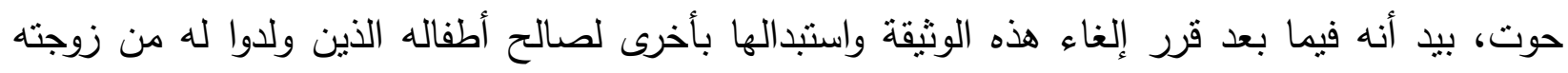

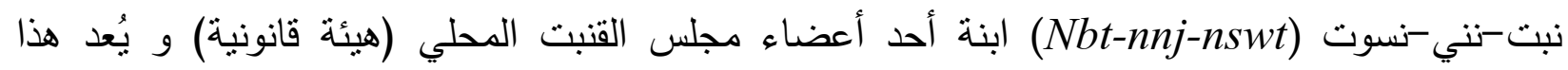
النص أيضا واحدًا من وثائق jmj.t-pr الفعلية الني وصلتنا من العصر الفرعوني. ونم الثهادة عليها من قبل ثلاثة أشخاص.

كذللك، يكثف نص بردية التبني الاستثائي، آنفة الذكر ، أن الزوج كرَّ أملاكه كلها لزوجته بعد أن

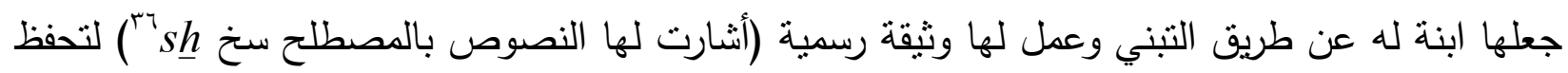

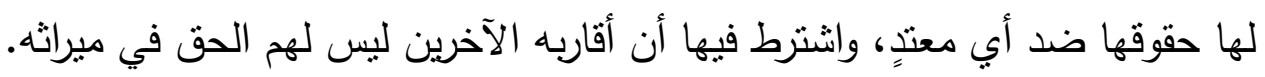

وفي القضية المشهورة المُسجلة علي بردية تورين، التي وقعت أحداثها خلال الأسرة العشرين، نجد أن

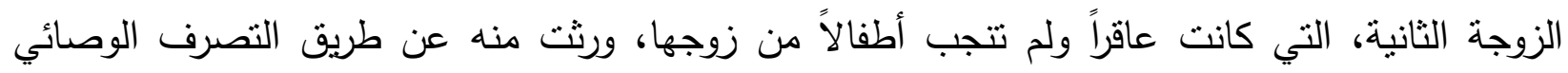

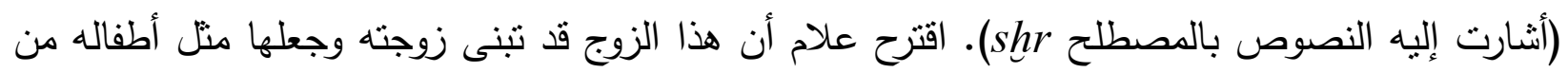

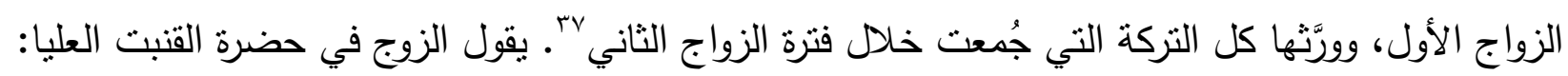
"لقد حضرتُ (أنني موجود) في حضرة الوزير وسُرات مجلس الأعيان

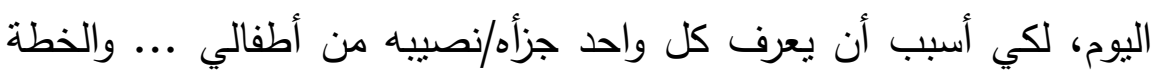
التي عملتها للمواطنة إنكسونجم، السيدة، الكائنة بمنزلي.

(Papyrus Turin 2021+Geneva D 409: 3, 9-10).

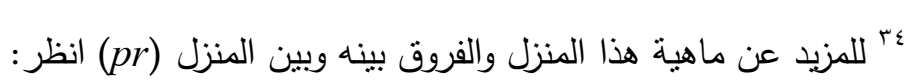
DEMARÉE, R.J., A House is not a Home - what Exactly is a Hut?, DORN, A. \& HOFMAN, T. (eds), Living and Writing in Deir el-Medine: Socio-historical Embodiment of Deir el-Medina Texts, Basel: Schwabe Verlag, 2006, $65 \mathrm{f}$.

35 GANLEY, «The Legal Deeds of Transfer from “Kahun”, Part One», 17 ff. FIG. 1 بr تم مناقثة هذه الوثائق، التي بموجبها نقل الميراث، باستفاضة في رسالة الدكتوراه الخاصة بي وهي قيد الإعداد، والتي تعنون بـ "مساهمات لقانون التوريث في مصر القديمة"، وهي تحت إثراف العلامة شفيق علام بجامعة توبنجن - ألمانيا.

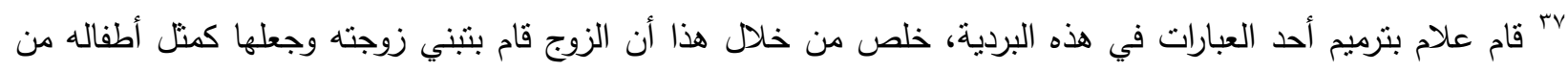
Allam, Papyrus Turin, 27. زواجه الثاني (انظر : 


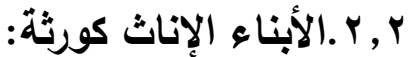

كما ذكرنا سابقًا أن البنات ورثن من والديهما عن طريق نظام التوريث العرفي ونظام التوريث

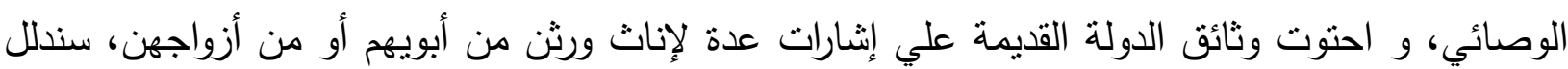

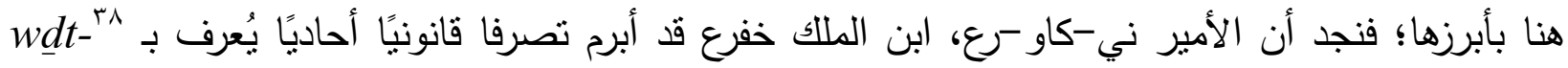

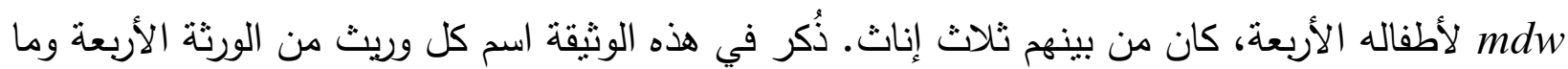

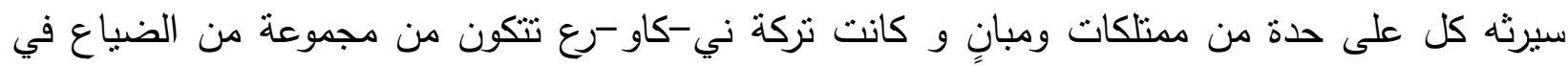

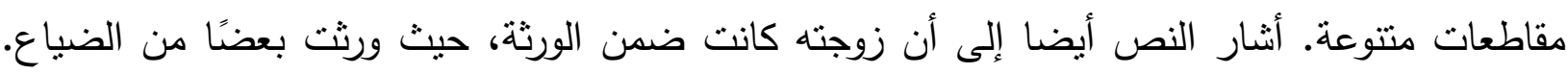
.(Inscription of $N j-k 3 w-R^{c^{r a q}}$ )

واحتوت المصادر النصية من الدولة الوسطى وعصر الانتقال الثاني علي أمثلة عدة توضح أن الإناث ورثن من والديهم تحت نظام التوريث الوصائي. من أهمها، لوحة بمتحف القاهرة مُسجلة تحت رقم التهال

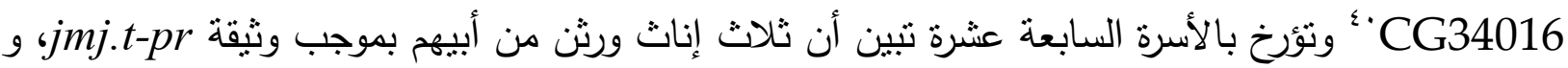

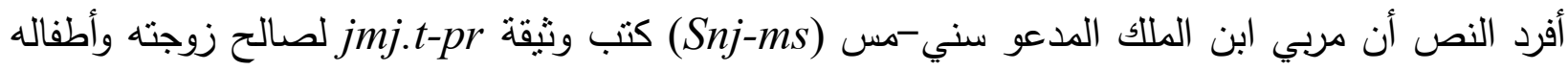
الأربعة في العام الحادي والعشرين من عهد الملك تحتمس الثالث، حيث تعاملت نلك الوثيقة مع التركة (ht)

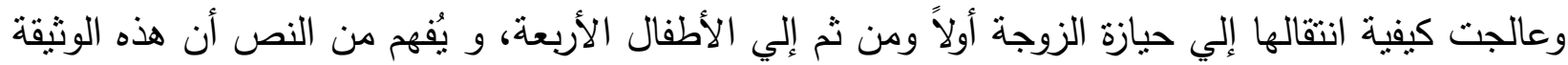

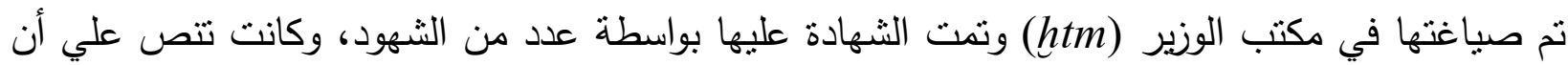
ممتلكات المورث سنوضع كوحدة واحدة، دون تقسيم، بعد وفاته في حيازة زوجته، السيدة هاجر ، طيلة حياتها،

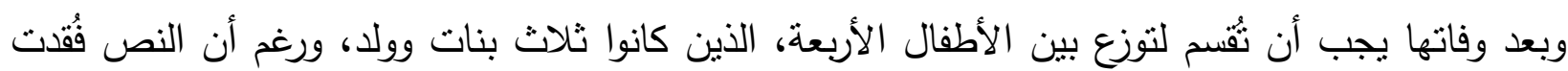
منه أجزاء عدة، إلا أنه من الجلي أن هناك ثمة نزاع وقع بين هؤلاء الورثة وبين امرأة مجهولة، يعُتقد أنها

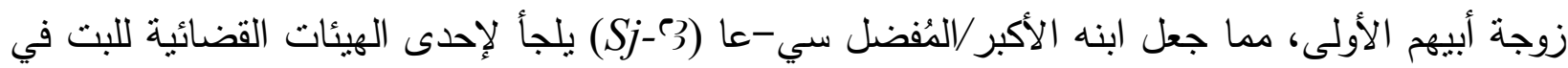
هذا النزاع. (

احتوت نصوص الأسرة السابعة عشرة أيضًا على مثال آخر يدلل على أن الإناث ورثن من والدهن، و

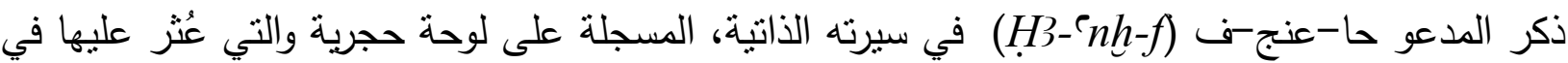

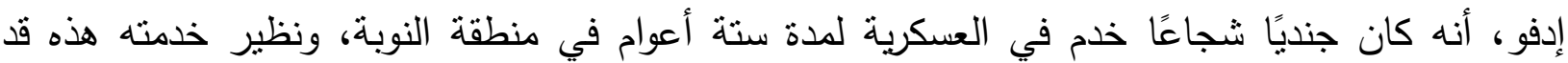
اكتسب ثلاثة أذرع من الأراضي، قسمها بينه وبين زوجته وأطفاله الستة، أعطى أحدهم لزوجته والثاني

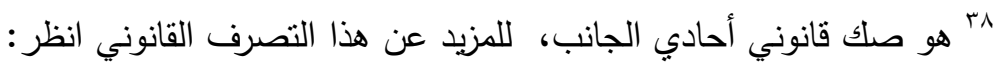
GOEDICKE, H .:«Bilateral Business in the Old Kingdom», DE 5, 1986, $82 \mathrm{ff}$.

${ }^{39}$ GoedicKE, H , Die Privaten Rechtsinschriften aus dem Alten Reich, 1970, $21 \mathrm{ff}$. PL. 3.

${ }^{40}$ SeTHE, K, Urk IV, 1065 ff.; SPAlinger, A., The Will of Senimose, Junge (ed.), Studien Westendorf, I, 631 ff. PL. 1.

${ }^{41}$ SPALINGER, The Will of Senimose, $637 \mathrm{f}$. 
لأطفاله الستة، والثالث ظل معه. احتوت سيرته الذاتية علي قائمة لأسماء أطفاله الستة، الذين كانوا ثلاثة ذكور وثلاث إناث.و يعكس هذا النقش ممتلكات أشخاص من طبقة اجتماعية دنيا، حيث إنهم كانوا يتعاملون مع قطع أراضي صغيرة جدا تقاس بوحدة الذراع الذي يساوي حوالي سبعة وعشرين منرا ونصف مربع، و من اللافت للنظر أن المرأة في هذا النقش حصلت على نفس مقدار الأرض التي حصل عليها الأطفال من زوجها.

$$
\text { تعويض / مكافأة لستة سنوات." لقد اكتسبت ذراعين من الأراضي؛ واحد من أجل ذوراعًا من الأراضي، يُعطى لأطفالي. ( هذام كتها، }
$$

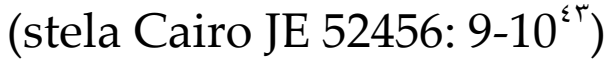

يقدم النص الهيراطيقي المُسجل على إناء اكسفورد من الأسرة نفسها دليلاً علي أن المرأة في العصر الفرعوني ورثت من شخص أجنبي عن أُسرتها، لم بربطها معه أية صلة دم. تم سرد تفاصيل هذه القضية بشكل مختصر ، و نجد أن أحدهم يُدعى تي -عا (Ttj-93) استقبل لاجئاً يُسمى منيو كبو (Mnjw-pw) وسمح له أن يعيش معه، وبعد وفاة هذا اللاجئ، قامت ابنته تي -عا بدفنه بناءً علي مشورة من زوجها، الذي قال لها: إذا دفنتيه سوف ترثيه و بهذا استحقت كل ممتلكاته، وخاصة أنه مات "أبتز" لا أولاد له، وبناء على كرم والدها تجاه هذا اللاجئ ودفنه استحقت ثلك المرأة ممتلكاته و يكثف هذا النص أن الميراث كان شرطا للافن ؛؛ يقول الابن، الراوي في النص:

"ولقد مات (أي اللاجئ)، ودفنته أمي، إنه زوجها نني من قال لها: ادفنيه وأرثي منه".

\section{(Bowl Pitt Rivers Museum ${ }^{\text {¿o }}$ )}

أفردت نصوص الدولة الحديثة أمثلة عدة لإناث ورثن من أبائهن وأزواجهن؛ يُقدم لنا النقش الموجود علي الجدار الثمالي والجنوبي لمقبرة كاتب الخزانة الملكية مس (MS) بَ بسقارة، والذي يؤرخ بالأسرة التاسعة

42 AlLAM, Women as Owners of Immovables in Pharaonic Egypt, 125-26.

${ }^{43}$ GUNN, B. :«A Middle Kingdom Stela from Edfu», ASAE 29, 1929, 5 ff.

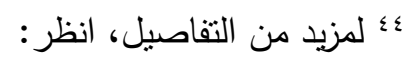

GARDINER, \& SETHE, Egyptian Letters to the Dead, $26 \mathrm{f}$.

45 GARDINER \& SETHE, Egyptian Letters to the Dead, 26 f. PL. 9; WENTE, Letters from Ancient Egypt, 1990, 216 No. 351.

بـ يوجد هذا النص علي الجدارين الثمالي والجنوبي في الحجرة الثانية من هيكل مقبرة مس؛ الجدار الثمالي محفوظ حاليا بالمتحف المصري بالقاهرة، أما الجدار الجنوبي فلا يزال بالهيكل في سقارة. اشتهرت قضية هذا النص باسم "قضية نزاع مائه

$$
\text { عام" أو قضية القرن. لتقسير، للمزيد انظر : بالهرة }
$$

GARDINER, A, The Inscription of Mes: A Contribution to the Study of Egyptian Judicial Procedure, SETHE, K. (ed.), Untersuchungen zur Geschichte und Altertumskunde Ägyptens IV, Leipzig, 1964, 1 ff.; ALLAM, S.:《 Some Remarks on the Trial of Mose», JEA 75, 1989, $103 \mathrm{ff}$. 
عشرة، سلسلة من الدعاوي القضائية التي استمرث نحو قرن ونصف بشأن ملكية الأراضي الخاصة بضابط

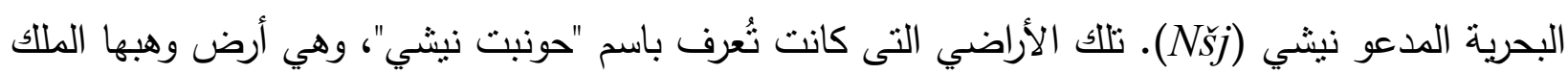

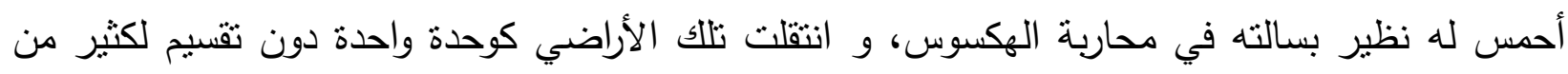
الورثة المُتعاقبين.

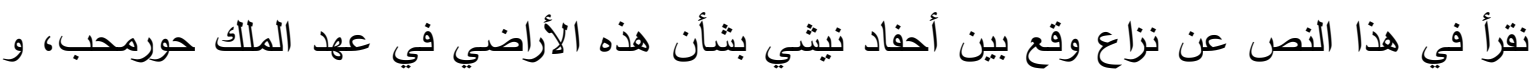

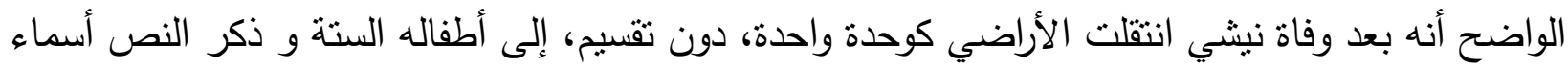

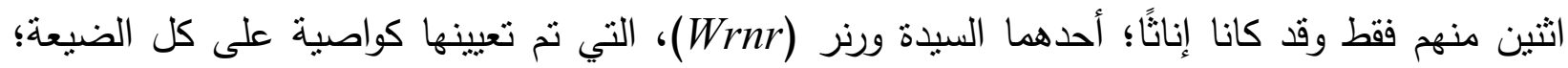

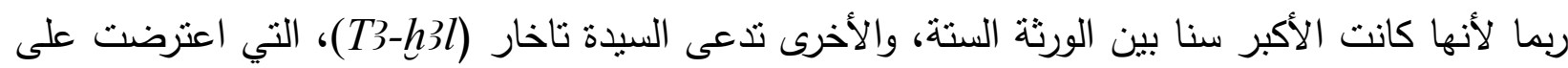

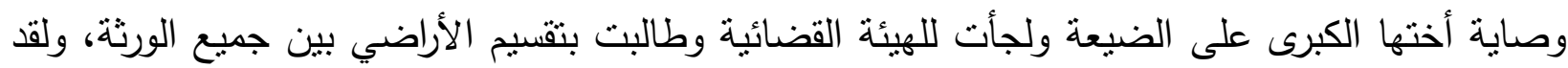
نجحت في ذلك، حيث أرسلت الهيئة القضائية واحدًا من نوابها ليقوم بتقسيم تلك الأراضي عيانًا بين الورثنة الستة، وليبين لكل منهم نصييه من الميراث و يروى مس حفيد السيدة ورنر جزيًا من أحداث هذه القضية التئية

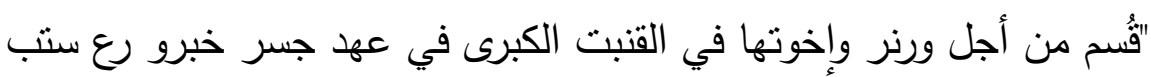

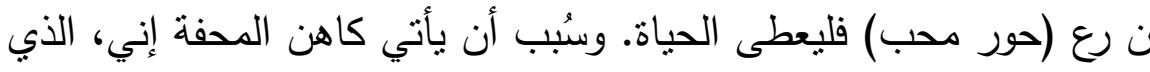

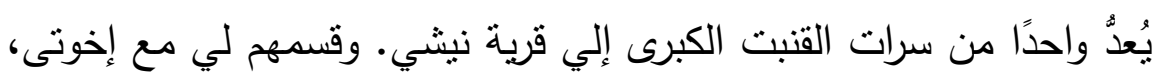
وجعلوا أمى/جدنى، المواطنة ورنر كواصية على أثقائها".

Inscription of $M s: \mathrm{N} 2-3)$

احتوى هذا النقش علي إثنارة أخرى لامرأة آلت إليها حصة زوجها من ثلأك الأراضي بعد وفاته؛

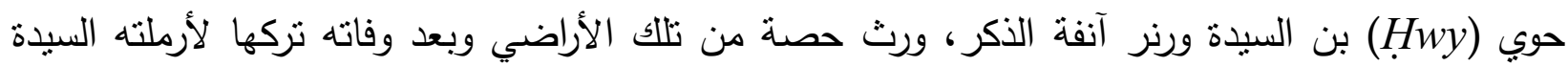

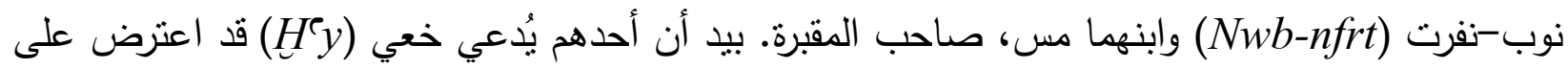

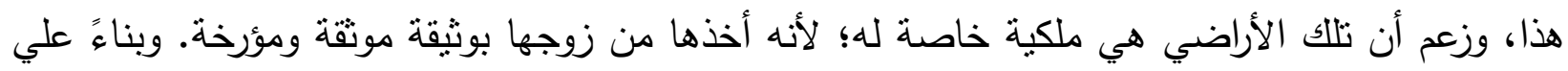

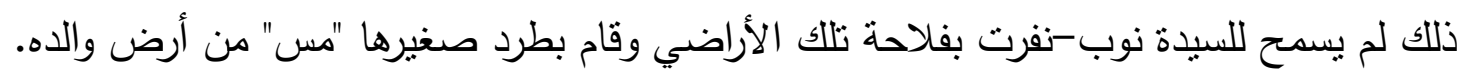
أوستراكا بتري (Ostracan Petrie $108^{\varepsilon v}$ (O) من عهر الملك سيتي الأول، و تسرد أن رجلاً من الطبقة الدنيا أبرم وثيقة jmj.t-pr لصالح أطفاله الستة، أربعة ذكور واثثين إناث، ورثوا منه بموجبها أملاكه

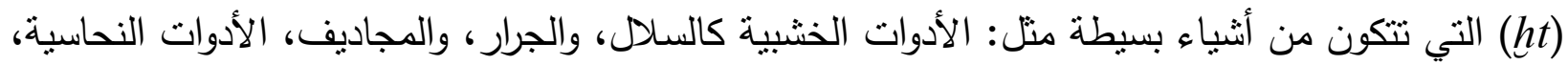

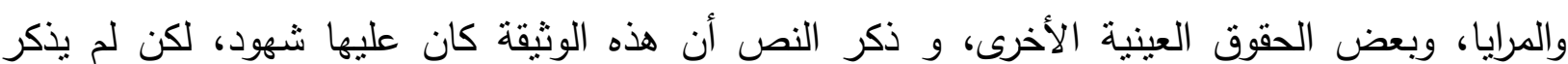
أسماؤهم.

47 KRI I, 1975, 409 § 172: 8.; KRITA I, 1993, 337 f. § 172: 8.; ALLAM, Hieratische Ostraka und Papyri aus der Ramessidenzeit, 89 ff. No. 57. 
قد تكون أوستراكا دير المدينة (Astracon DeM 764) عبارة عن تمرين نسخي للمتدرب أو شخص كان سيتم تدريبه في الأمور القانونية، و هي تؤرخ بالأسرة التاسعة عشرة ويتتاول نصها تقسيم ممتلكات غير محددة بين ثلاث فئات من الناس، ربما هم من عائلة واحدة. الزوج (الحي) والزوجة ولئة والأطفال،

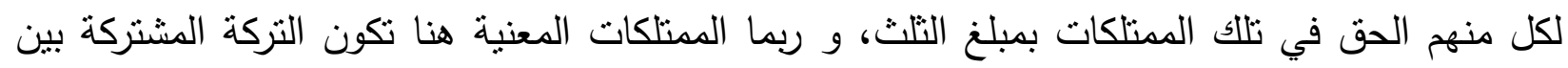

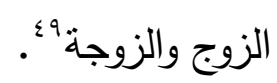

تسرد أوستراكا جاردنر (Ostracon Gardiner 55) نزاعًا وقع بين زوج ووالد زوجته الأولى بشأن

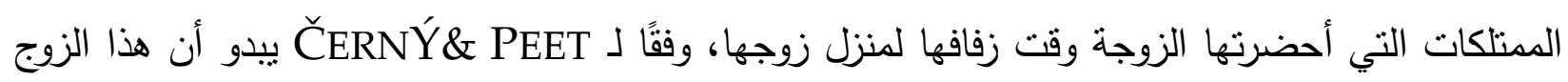

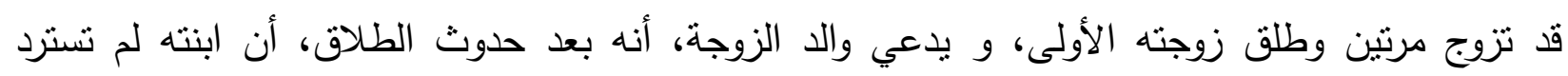

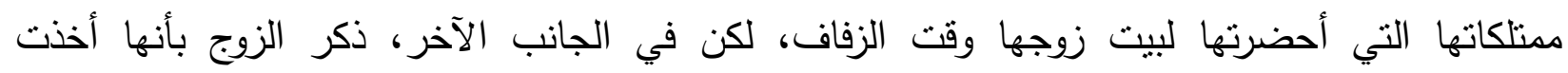

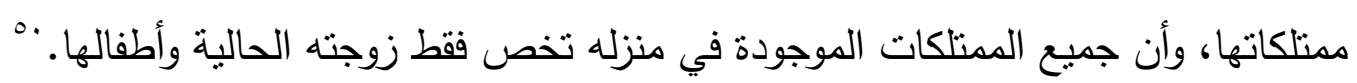

وهناك أوستراكا أخرى موجودة في المتحف البريطاني (Ostracon BM 5624) من عهد رمسيس الثالث، تروي نزاعا بين خع -نون (H3yn)

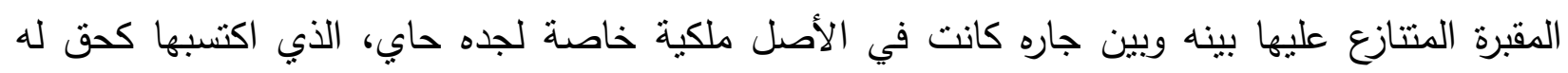

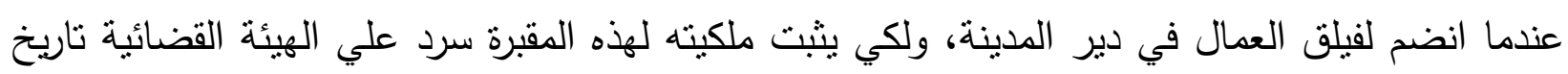

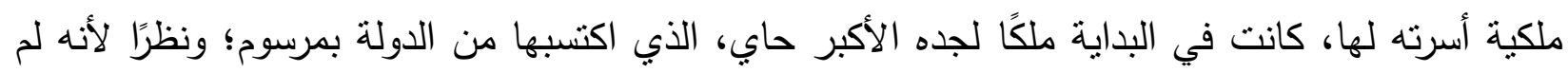

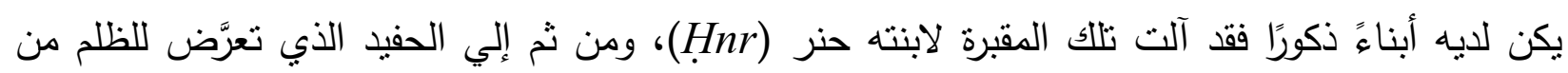
جاره خع -نون.

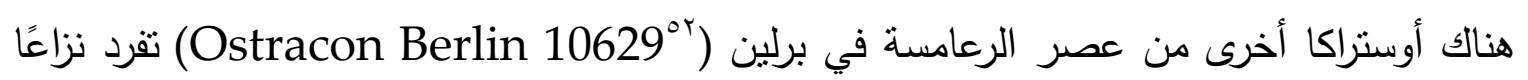

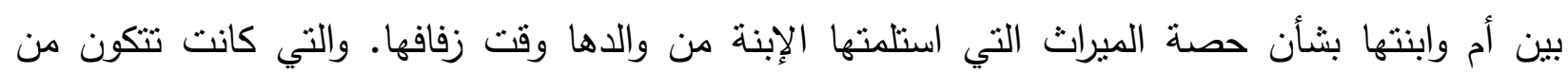

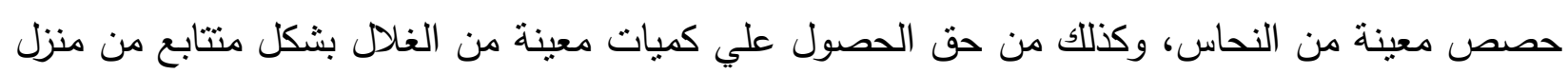

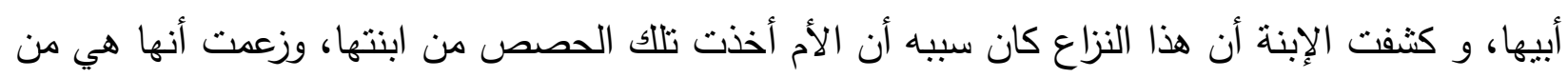

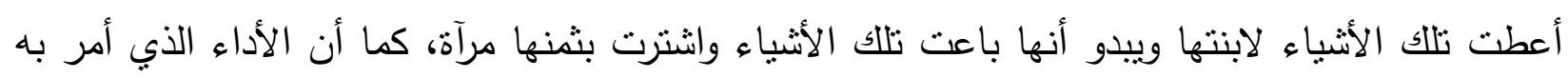

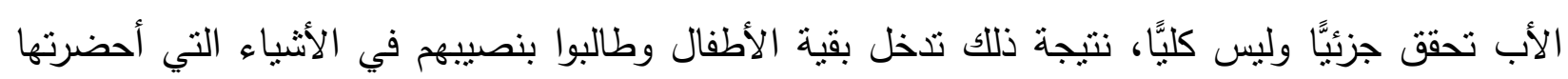

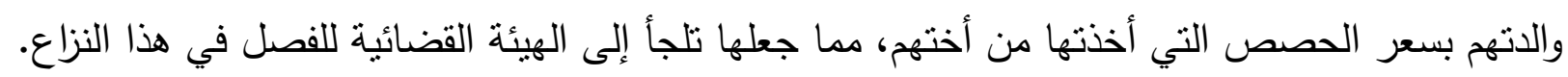

48 GRANDET, P., Catalogue des Ostraca Hiératiques non-Littéraires de Deîr el-Médînéh, Vol.8, 2000, 166; KRUCHTEN, J.:« Derechef l'Ostracon DM 764», GM 198, 2004, $39 \mathrm{ff}$.

${ }^{49}$ TOIVARI-VIITALA, J.:« O. DeM 764: A Note Concerning Property Rights», GM 195, 2003, 96.

${ }^{50}$ ČERNÝ \& PEET, A Marriage Settlement of the Twentieth Dynasty, $38 \mathrm{f}$.

${ }^{51}$ BLACKMAN, A.: « Oracles in Ancient Egypt II», JEA 12, 1926, 176 f. PLS. 34-5.

52 ČERNY, J.: « Le Culte d'Amenophis I chez les Ouvriers de la Nécropole Thébaine», BIFAO 27, 1927, 177

f.; KRI V, 574; KRITA V, 445, A.237.; ALLAM, Hieratische Ostraka und Papyri aus der Ramessidenzeit, 27 ff. No. 7. 
الأطفال الخمسة، من قررت السيدة ناونخت أن تعطي لهم ممتلكاتها الخاصة نظير كونهم بارين بها،

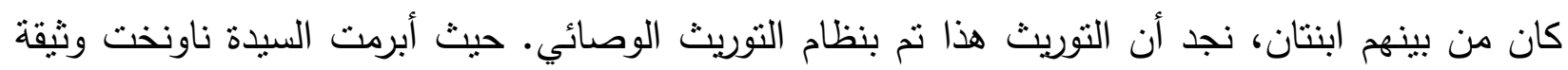

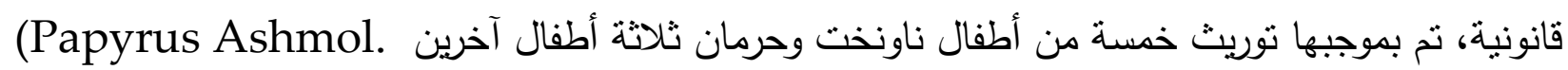
.Mus. 1945.97)

ويستتبط من النزاع، المُسجل على بردية من عصر الرعامسة محفوظة بالمتحف البريطاني

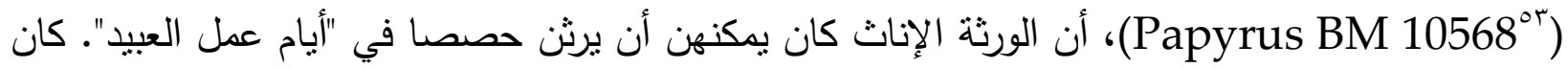

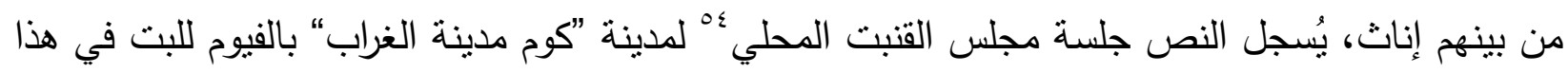

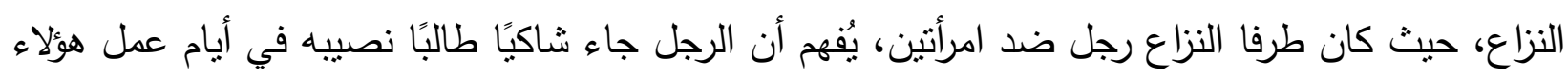

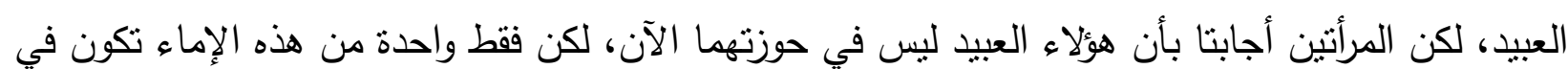
حيازتهما. وتُقدم لوحة العمرة (Stela Amarah) من الأسرة العشرين دليلاً على أن البنت ورثت من أبيها

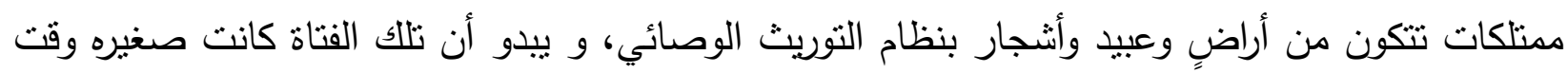

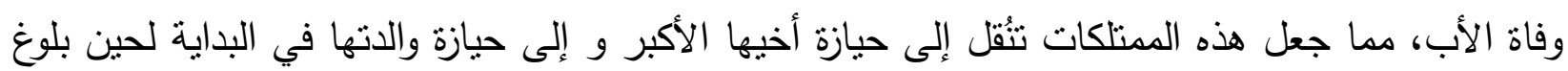
هذه الفتاة السن القانوني.

تُقدم النصوص المدونة على تمثال القاهرة رقم (Statue Cairo CG 42208) بَالمؤرخ من الأسرة

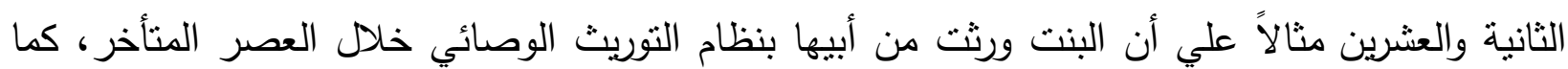

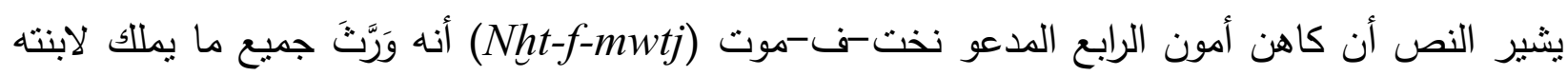

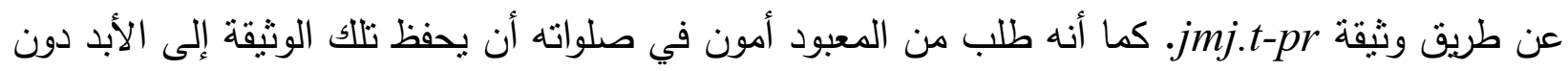

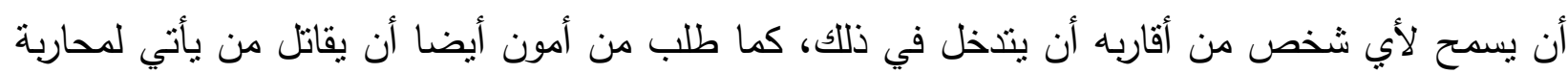

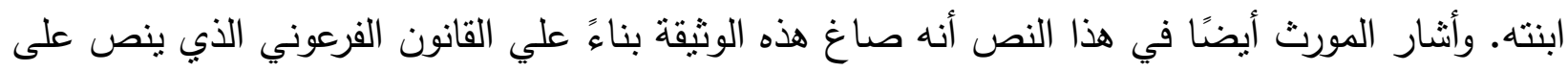

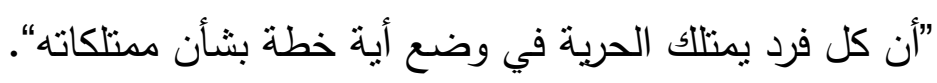

53 ALLAM, «Ein Erbstreit um Sklaven (Papyrus BM 10568)», 89 ff. PL. 19.

؛ُ عندما أصبحت مصر إمبراطورية منرامية الأطراف، احتاج الملك والوزير تفويض بعض المسؤوليات القانونية إلى المجالس المحلية، التي انتشرت في جميع أنحاء مصر . وخير مثال على ذلك هيئة القنبت المحلية تلك الموجودة في دير المدينة. للمزيد عن هذه الهيئة، انظر : ع الني VersteEG, R., Law in Ancient Egypt, Durham, North Carolina, 43 ff.; Allam :«Egyptian Law Courts in Pharaonic and Hellenistic Times», JEA 77, 1991, 109-27.

${ }^{55}$ FAIRMAN, H :.«Preliminary Report on the Excavations at Sesebi (Sudla) and 'Amārah West, AngloEgyptian Sudan, 1937-38», JEA 24, 1938, 151 ff. PL. 11.3.; THÉODORIDÈS, A.:« La Stele Juridique d'Amarah», RIDA 11, 1964, 45 ff.

${ }^{56}$ JANSEN-WinKeLn, K., Ägyptische Biographien der 22. und 23. Dynastie, vol.2, 1985, 44 ff., 453 ff. 
أفردت لوحة التبني الخاصة بالأميرة نيتوكريس من الأسرة السادسة والعشرين أن ابنة الأخ ورثت من

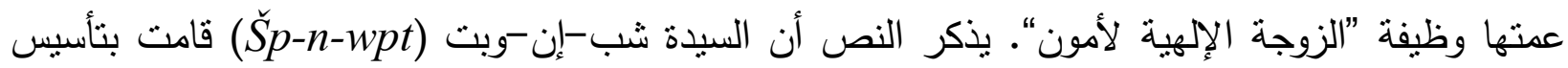

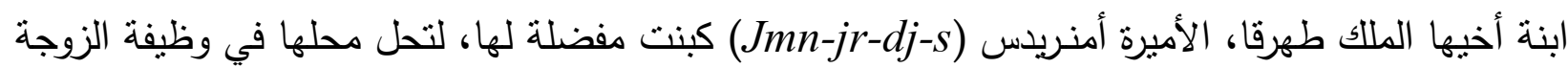
الإلهية لأمون. وبالمثل قامت السيدة شب-إن-وبت بتبني الأميرة نيتوكريس، ابنة الملك بسمانبك الأول، وترسيمها كوريثة المنصب من شب-إن-وبت وكذلك المنلكات (ht). يسرد النص شرعية لها بعد ابنة

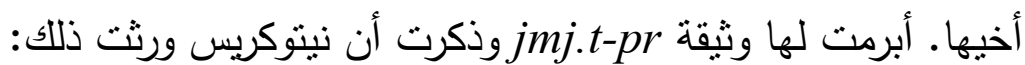

"بعد ذلك وصلت (نيتوكريس) إلى زوجة الإله شب-إن-وبت عندما رأتها

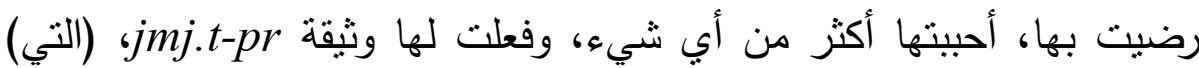

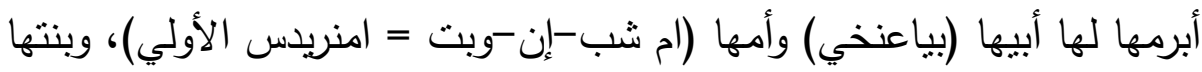

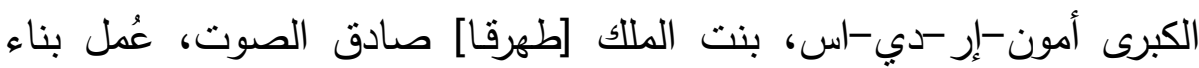
على رأيهم في مكتوب قائلين: نحن نعطي للك كل نركتتا في الريف والمدينة، وأنت ستثتنتن علي عرشنا، وستبقين حتى نهاية الخلود".

(Stela Nitocris Adoption: $15 \mathrm{ff}^{\circ{ }^{\circ v}}$ )

احتوت النصوص الديموطيقية للأسرة السابعة والعشرين علي أمثلة عديدة لإناث ورثن من أبائهن.

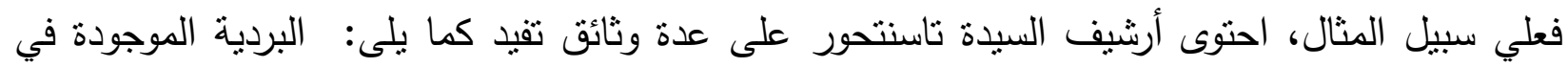

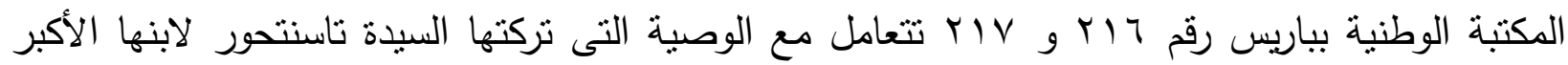

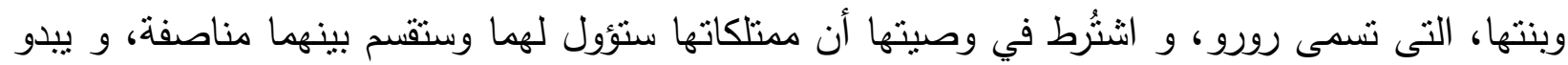
أن الموصية كتبت هذه الوصية خلال حياتها حيث إنها وضعت في الوصية شرطا مستقبليا بشأن أي طفل

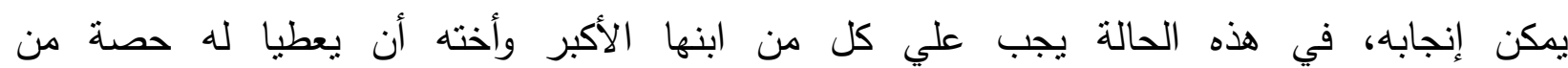
الميراث (Papyrus Bibl. Nat 216; Papyrus Bibl. Nat 217)

أيضا، احتوى الأرشيف السابق على ثلاث برديات أخرى تتناول عملية نقل الميراث الخاص بالزوجين باشر ن است (P3-snt-n-Hrr

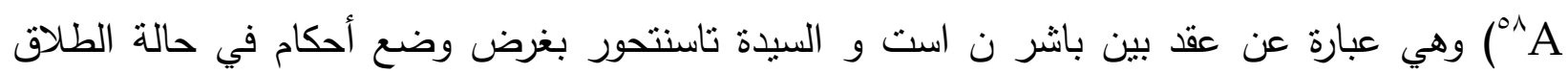

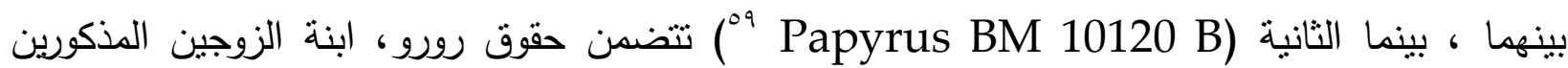

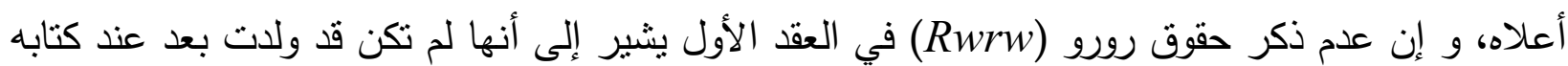

${ }^{57}$ CAMINOS, R .: «The Nitocris Adoption Stela», JEA 50, 1964, 71 ff. PLS. 7-10.

58 ERICHSEN, W, Auswahl Frühdemotischer Texte, Vol.I, 1950, 31 f.; LÜDDECKENS, E., Ägyptische Eheverträge. Ägyptologische Abhandlungen, vol.I, 1960, 16 ff. No. 6.; PESTMAN, Les Papyrus Démotiques de Tsenhor, vol.I, 1994, 46 ff. №. 3.

59 ERICHSEN, Auswahl Frühdemotischer Texte, 33 f.; PeSTMAn, Les Papyrus Démotiques de Tsenhor, 50 ff. №. 4, PL. 5, 5a. 
هذا العقد. بعد 9 ( عامًا من كتابة الوثيقة الثانية قام باشر ن است بترتيب جديد يتوافق مع التغييرات التي حدثت مؤخرًا. وتشجل ثالث البرديات (Papyrus Turin 2126) أن الزوجين المذكورين أعلاه قد رُزقا بطفل آخر يذُعي إرتورو (Jr.t.w-r=w). لهذا جاء في هذا الترتيب أن باشر ن است ذكر أن ميراثه سيقسم بين طفليه بالتساوي، و تم تسجيل الوثيقة المُصاغة لصالح رورو على بردية تورين، ومن المحتمل أن أخاها

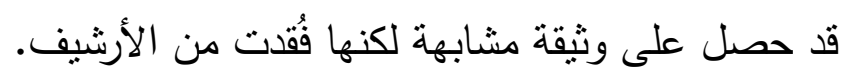

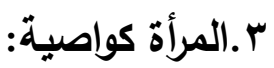

أثنارت وثائق الميراث بشكل غير مباشر إلى تعيين الأم واصية على أطفالها القُصَّر لإدارة أصول زوجها نيابة عنه حتى ييلغوا السن القانوني. علي سبيل المثال، في القضية المُسجلة علي اللوحة الموجودة بالمتحف المصري بالقاهرة (Stela Cairo CG 34016) آنفة الذكر، نجد أن الزوجة احتفظت بممتلكات

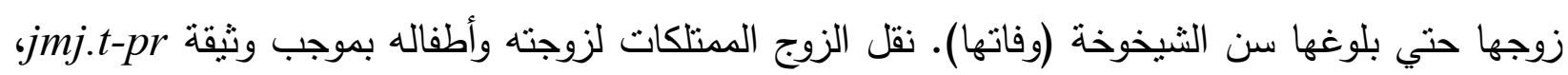
التى احتوت على شرط ضمني يقضي بأن الزوجة يُجب أن تمسك تلك الممتلكات طوال فتره حياتها، كما أفاد النص أن هذه الممتلكات نُقلت لها كوحدة واحدة دون تقسيم من أجل إدارتها، و أشنار SPALINGER أن دور الزوجة في ثلك القضية كان دور "الوصي" على أطفالها رغم أن النص لم يدعم هذا الدور "، و أكد علام أن الزوجة يمكن أن تتدخل في الميراث المتروك من الأب للأبناء كوسيط، في هذه الحالة يمكن للأطفال أن يرثوا فقط عن طريق والدتهم بَّ. و يبدو أن هذا الدور كان يوثق بين الزوجة وزوجها من أول يوم لهما معا، حيث أشارت عقود الزواج أيضًا أن الزوجة ستعمل كواصية على الأطفال، حيث كان الزوج يعد زوجته بأن أطفالها سيكونون مالكين لكل ممتلكاته، و يبدو أن الزوجة حصلت علي هذا الميراث نيابة عن أطفالها من الزوج بّو اشترط الزوج في أحد بنود عقد الزواج على زوجته بأن تُعطي هذا الميراث لأولادهم فقط. "بينما لن تكوني قادرة علي إعطائها (الأملاك) لطفل آخر غير الأطفال الذين

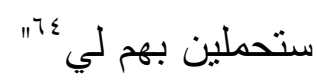

منل الابن الأكبر، عملت البنت الكبرى أيضًا كواصية لإخوتها الأصغر منها سنا، حتى لو كانت الأسرة تمتلك طفلا ذكرا، كانت الابنة الكبرى مؤهلة للعمل كواصية على التركة الموروثة وعلى أثقائها

${ }^{60}$ Pestman, Les Papyrus Démotiques de Tsenhor, 80 ff. PLS. 14, 14a.

PernigotTI, S , Due Papiri Demotici di età Persiana Scritti in Onore di Orsolina Montevecchi, Paris, 1981, 285 ff.

${ }^{61}$ SPALINGER, The Will of Senimose, 633 No. 6.

${ }^{62}$ AlLAM, S. :«Quelques Aspects du Mariage dans l'Égypte Ancienne», JEA 67, 1981, 120.

${ }_{63}$ Pestman, P., Marriage and Matrimonial Property in Ancient Egypt: A Contribution to Establishing the Legal Position of the Woman, Leiden: Brill, 1961, 121.

${ }_{64}$ PeStMAN, Marriage and Matrimonial Property in Ancient Egypt, 121. 
القُصر ، ونظير دورها هذا، كان لها الحق في حصة إضافية من الميراث بالإضافة إلى نصيبها المستحق

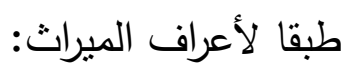

"لو مات الرجل دون طفل ذكر ، وكان لديه إناث، يجب أن تقسم أملاكه الي

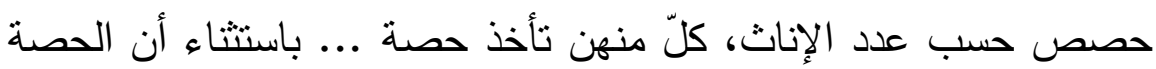

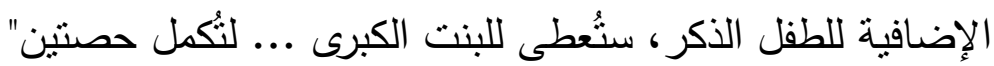

(Codex Hermopolis col. 9: 14-17)

كما ذكرنا آنفًا في سلسلة الدعاوي القانونية المُسجلة علي جدران مقبرة مس في سقارة. أن التركة

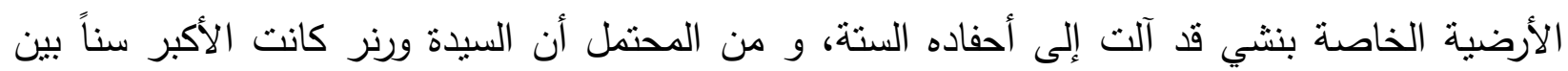

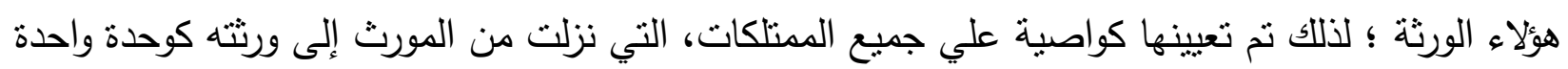

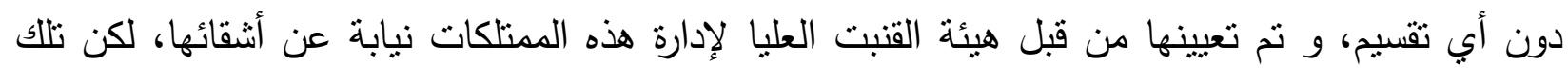

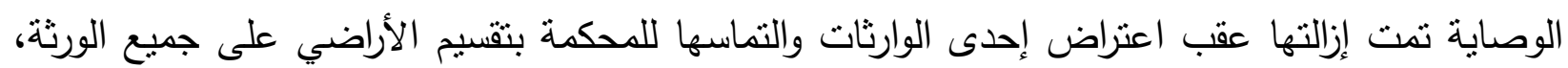

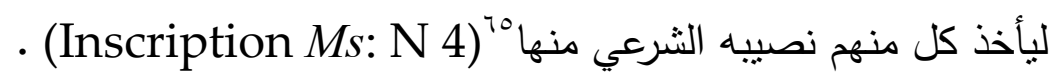
؛ ـالمرأة كثاهدة على الوثائق المتعلقة بالميراث :

نجد أن المرأة الفرعونية ظهرت شاهدة على الوثائق المُبرمة بشأن الميراث؛ فمثلاً في الوثيقة القانونية

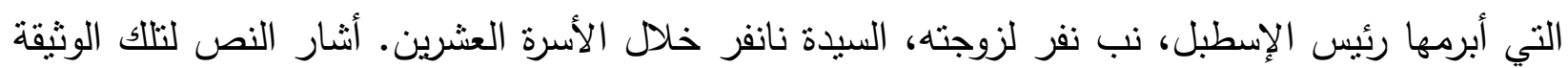

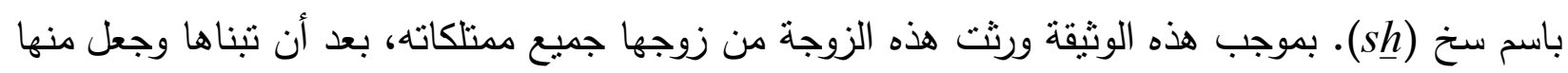

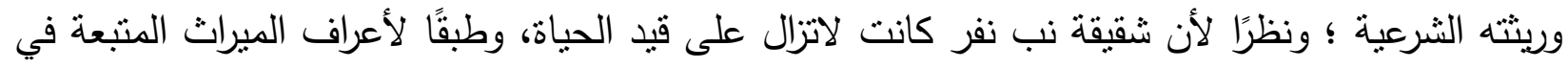

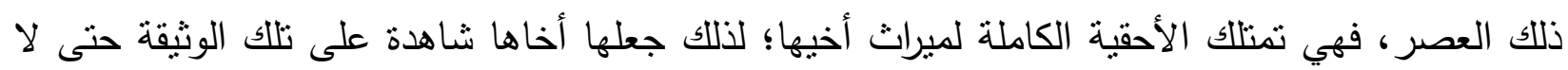
يمكنها الاعتراض مستقبلاً والمطالبة بالمبراث. علاوة على ذلك احتوت قائمة الثهود أيضًا على شاهدة أخرى

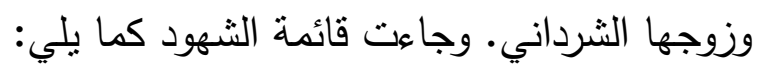

$$
\begin{aligned}
& \text { في حضور العديد من الثهود } \\
& \text { - رئيس الإسطبل ريري } \\
& \text { - رئيس الإنطبل كا-إري-سو } \\
& \text { - رئيس الإسطبل بن-إيري، ابن دوا-نفر برئ }
\end{aligned}
$$

${ }^{65}$ Versteeg, Law in Ancient Egypt, 147.

"T اقترح علام قراءة هذا الاسم هكذا.

AllaM, A New Look at the Adoption Papyrus (Reconsidered), 191. 


$$
\begin{aligned}
& \text { - في حضور رئيس الإسطبل نب-نفر، ابن عن-ر -كا-ايا } \\
& \text { - في حضور الثرداني با-كا-من }
\end{aligned}
$$

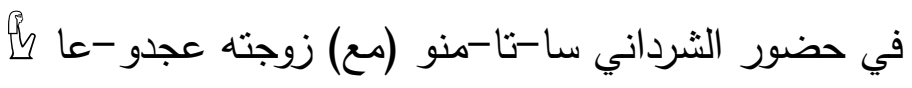

كذللك، احتوت الوثيقة التي أبرمتها السيدة نانفر لصالح أطفالها بالتبني على خمسة شهود من بينهم

ثلاث سيدات. وجاءت قائمة الثهود كما يلي:

$$
\begin{aligned}
& \text { في حضور العديد من الثهود } \\
& \text { رئيس الإسطبل سوتخ-م-حب } \\
& \text { مغنية سوتخ تا-و -حري لون } \\
& \text { المزارع سو -عو -أمون } \\
& \text { في حضور رئيس الإنطبل نب-نفر، ابن عن-ر -كا-ايا } \\
& \text { في حضور الثرداني با-كا-من }
\end{aligned}
$$

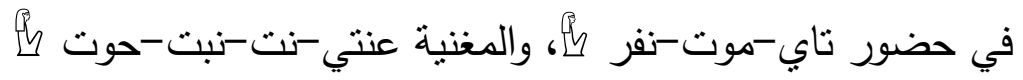

وفي الصراع الذي نشب بين خعي (Hy) وأسرة حوي (Hwy) بن أونر من سلالة نشي بشأن

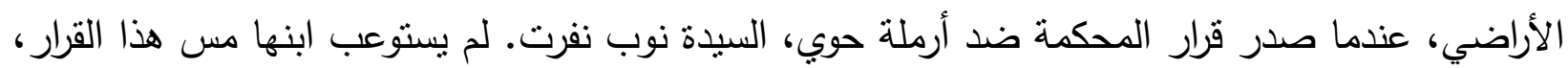
ولم يجد في يديه أية حجج أخرى ضد ادعاءات خصمه خعي؛ لذلك قام بتلخيص التاريخ السابق للملكية، وذكر أن الأراضي قيد النزاع، كانت قد مُنحت لجده الأكبر من الملك أحمس الأول، وذكر أنه كان من نسله،

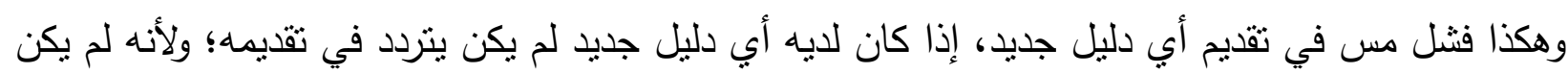
في موقع قوي فلم يتمكن من مخاطبة المحكمة الرسمية، لكنه حصل على طريقة واحدة فقط للاستئناف

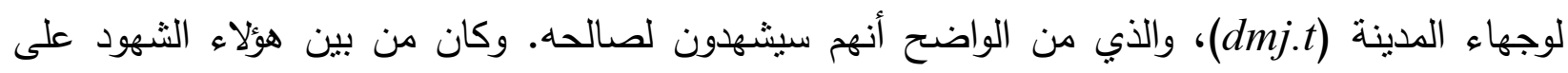

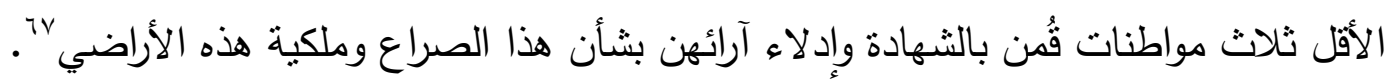
كثف هذا النزاع أيضًا عن دور المرأة كثاهدة، بعد أن قاضت السيدة تاخارو شقيقتها السيدة أونر من

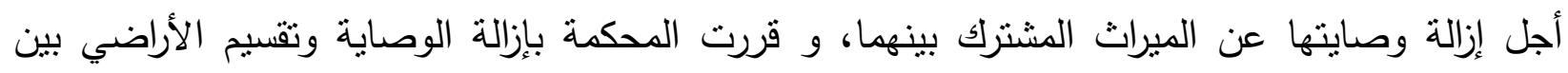

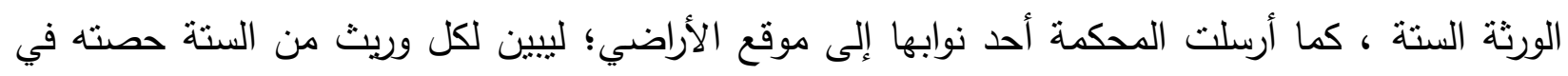




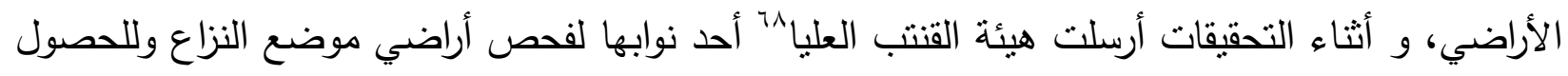

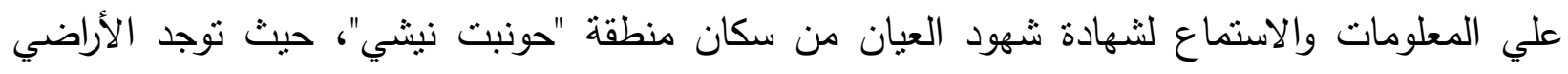

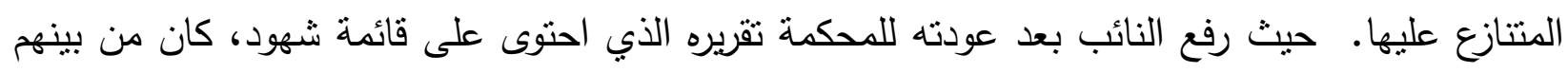

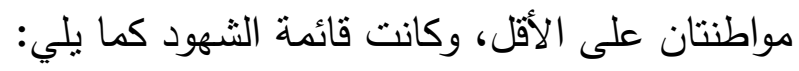
قائمة أسماء شهود نشي

$$
\text { المواطنة كا-كايطن }
$$

$$
\begin{aligned}
& \text { الجندي --- با-كا } \\
& \text { المجموع أربعة أشخاص } \\
& \text { هـالمرأة المملوكة (الأمة) كجزء من الميراث: }
\end{aligned}
$$

أفادت النصوص المصرية أن المرأة المملوكة في مصر القديمة كانت جزءًا من أملاك سيدها، يحق له

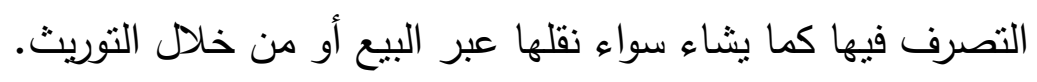

و كثف نص بردية كاهون أن الممتلكات التى ورثها واح من أخيه الأكبر ، عنخ رن شملت عددًا معينًا من

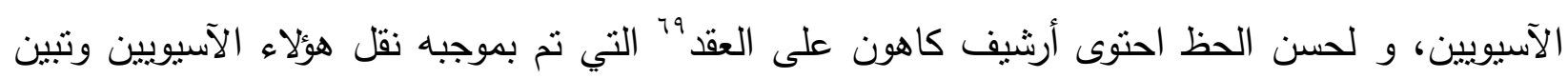

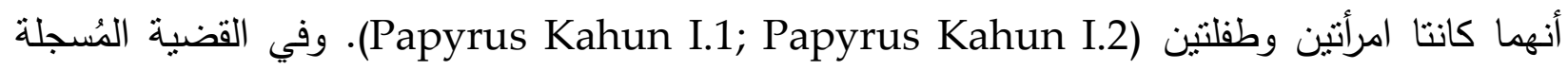

^^ كانت هذه الهيئة نوجد في المدن الرئيسة، وكان يترأسها الوزير. تم اختيار أعضاء كل منها من كبار الثخصيات الذين كانوا أهم المسئولين الحكوميين وأهم المسئولين القضائيين في مصر، لونئه وبما أن الملك لم يكن الثخصية المركزية في الجهاز

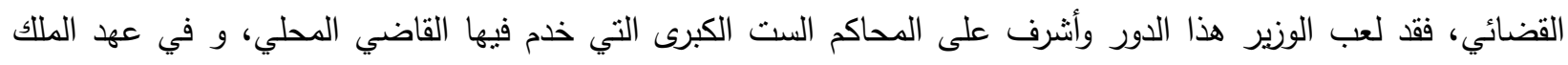
حورمب نم إعادة تنظيم الآلية القضائية وإنشاء محكمتين دائمتين إحداها في هليوبوليس والأخرى في طيبة. Versteeg, Law in Ancient Egypt, 40 ff.; Allam, Egyptian Law Courts in Pharaonic and Hellenistic Times, $111 \mathrm{ff}$.

79 هذا العقد يكون عبارة عن شراء أربعة من الآسيويين بواسطة واح من شقيقة عنخ كن، وهي تؤرخ بالعام و من عهد

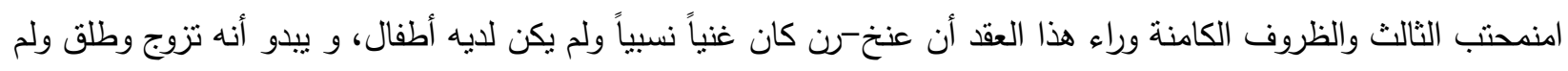

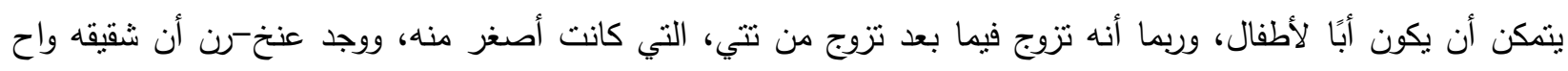

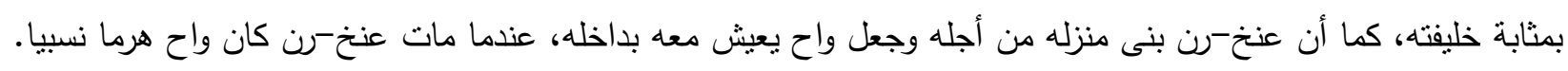

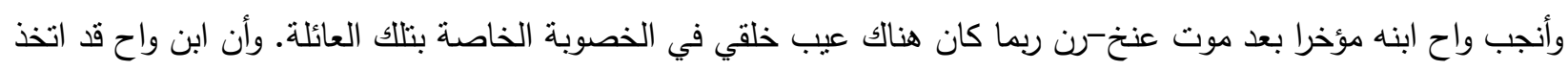
لحفظ حقوق العائلة. هذه الظروف التي كمنت خلف هذه العقود أن العائلة كانت تهنم بتركة محددة في ظروف غناب فئ فيها فئ إنتاج العديد من الأطفال، حيث إن العلاقة كانت بين عنخ-رن وواح المتقاربين في العمر يحيطها الود والوئام. GANLEY, A.:The Legal Deeds of Transfer from Kahun, Part One, 26. 
على بردية التبني الاستثنائي نجد أن رئيس الإسطبل وزوجته قاما بشراء أمة معًا، وقد أنجبت هذه الأمة ولدًا

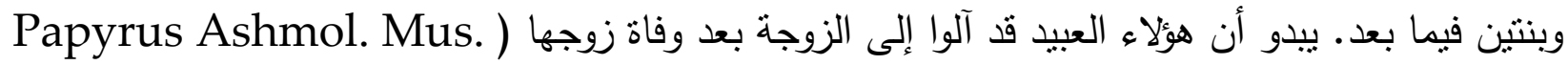
1945.96)، وبردية المتحف البريطاني (Papyrus BM 10568) تروى عن نزاع وقع بين شركاء الميراث، يُفهم من النص أن هذا الميراث كان عبارة عن "أيام عمل" بعض العبيد والإماء. كما أن التركة التي نقلها مربي الإله أمون-خعو لزوجته الثانية إنكسونجم كانت تتكون من عبدين وأمتين

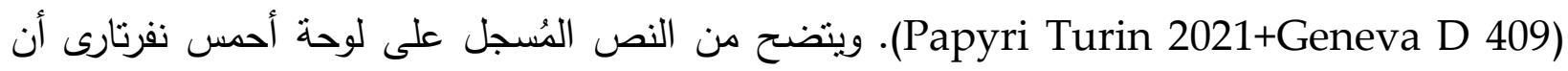

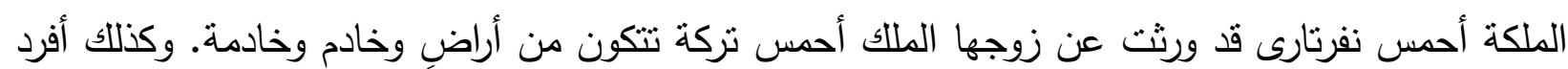

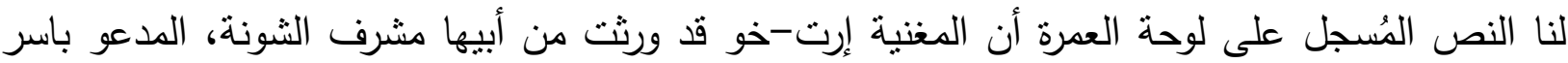
تركة تتكون من أراضٍ وعبيد ذكورا وإناثا وأثنجارًا. أخيرا، تكثف لوحة عثر عليها بمعبد الكرنك “من الأسرة الثانية والعشرين أن الابن قد ورث من أبيه تركة

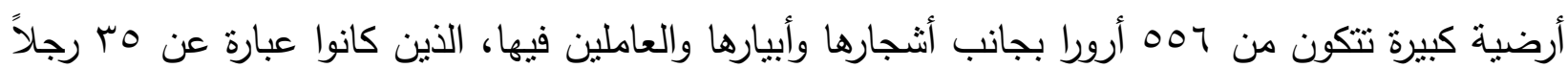

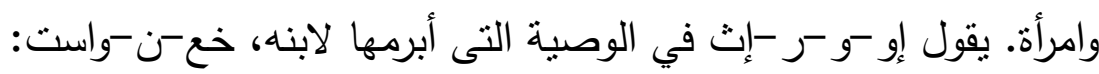
"مجموع الأراضي المتتوعة: 007 أرورا و وب رجلاً وست، مع أبيارها وأنثجارها

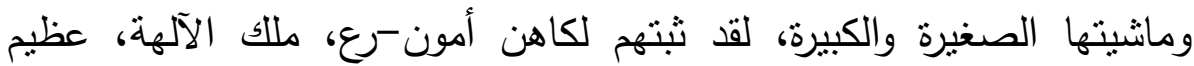

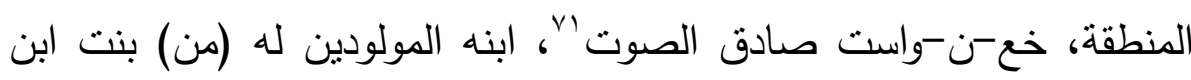

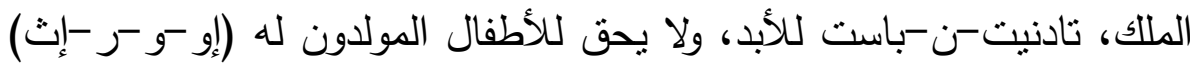

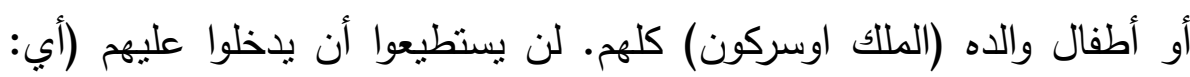

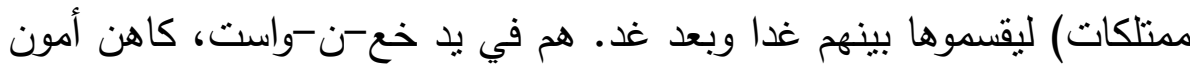

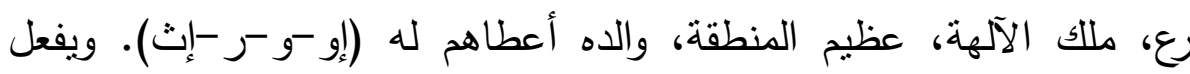
إعطائهم تماما من ابن لابنه ومن وريث لوريثه".

(Stela Apanage: 22 ff.)

النتائج:

يتضح من الأمثلة المسردة بأعلى أن المرأة عبر التاريخ المصري القديم عملت كمورثة منذ الأسرة

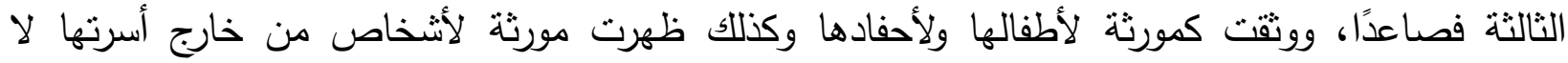
يربطهم بها صلة دم و هؤلاء الأثخاص اكتسبوا حق التوريث من خلال تطبيق نص القانون الفرعوني الذي وناي

${ }^{70}$ LEGRAIN, G. :《 Deux Stèles trouvées à Karnak», ZÄS 35, 1897, 12 ff; JANSEN-WINKELN, K.:《 Zu Einigen Religiösen und Historischen Inschriften», CdE 67, 1992, 240 ff.; RITNER, The Libyan Anarchy: Inscription from Egypt's Third Intermediate Period, $271 \mathrm{ff}$.

لو لو ان التركيبة ماع خرو تدل على المتوفي فكيف انه تم توريثهم لانسان متوفٍ . 
ينص على من يدفن يُعطى الميراث، كما استطاعت المرأة أن تمنلك وتورث جميع أنواع الممتلكات منل

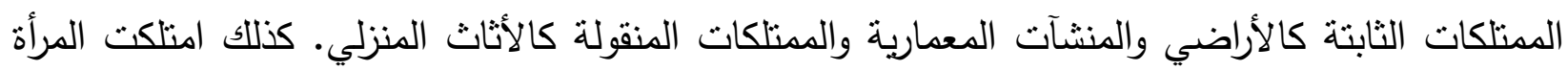

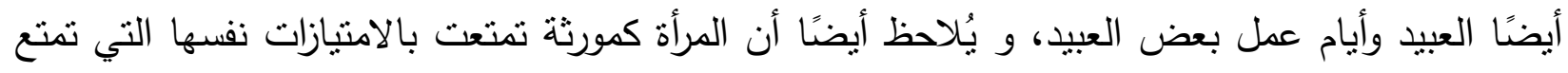

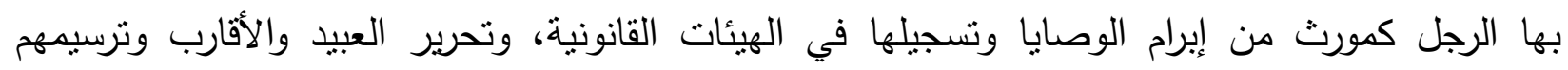

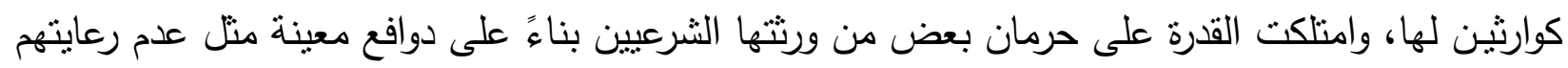
لها وقت شيخوختها.

كثفت الوثائق أيضًا أن المرأة لم ترث من زوجها طبقًا لأعراف الميراث المتبعة في مصر القديمة، كما

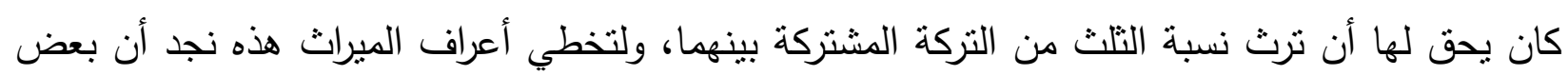

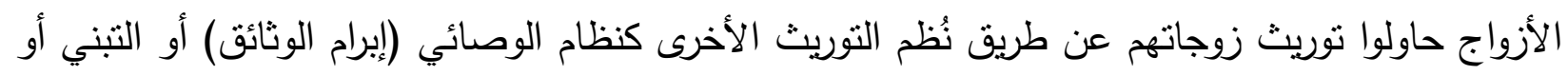

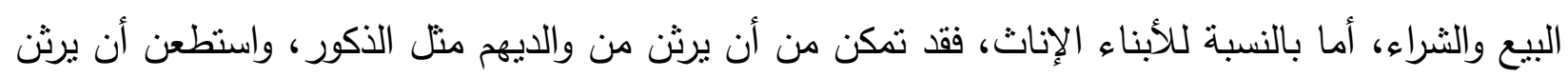

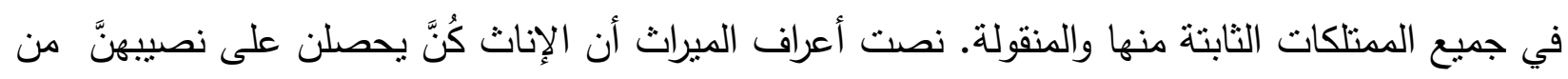

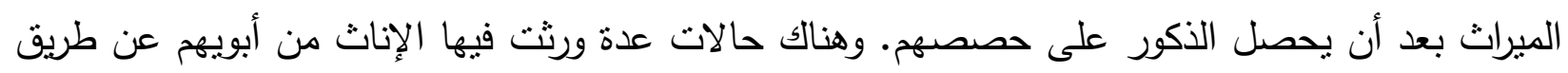

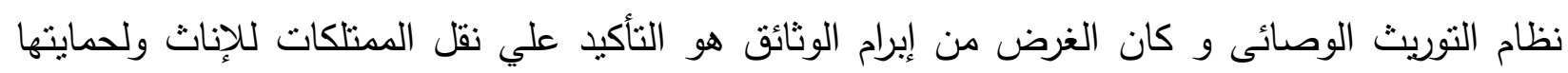

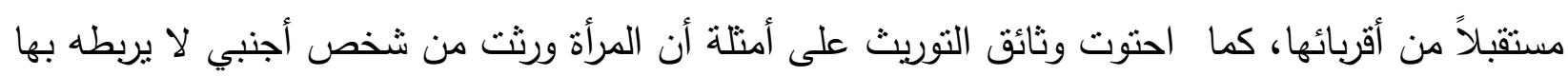

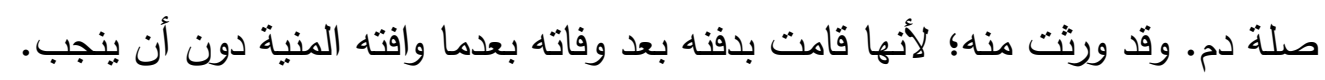

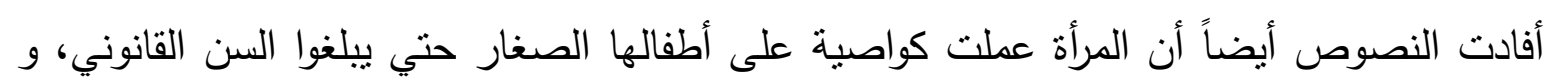
نجد في حالات عدة أن التركة نُقلت إلي الزوجة كوحدة واحدة دون تقسيم من أجل إدارتها نيابة عن أطفالها،

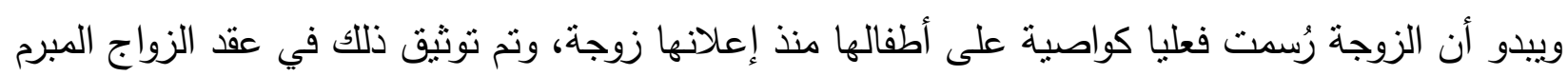

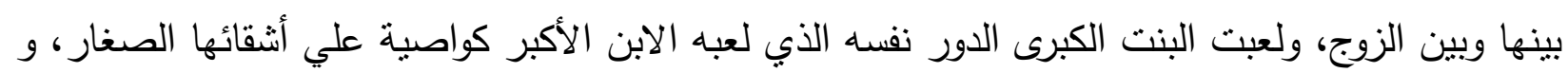

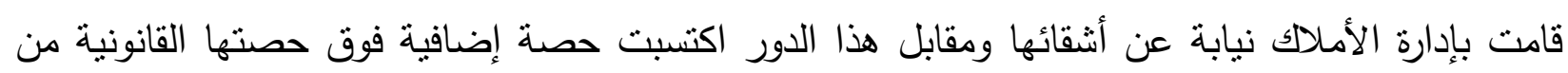
الميراث، كما يبدو أن البنت الكبرى كان يحق لها أن تمسك الأملاك إلى حين أنى أن يطالب شركائها في الميراث نصييهم من التركة.

يتضح أيضا أن النساء في مصر الفرعونية عملن كثهود على الوثائق المبرمة بشأن الميراث،

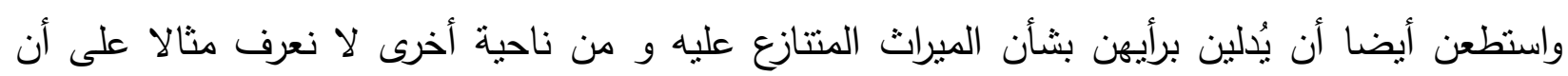
المرأة كانت ضمن أعضاء الهيئة القانونية التي بتت في أئان أمور الميراث حتى الآن.

وأثنتت الوثائق أيضًا، أن المرأة كانت منلها منل الرجل حين يفقد حريته، يصبر جزءًا من أملاك سيده،

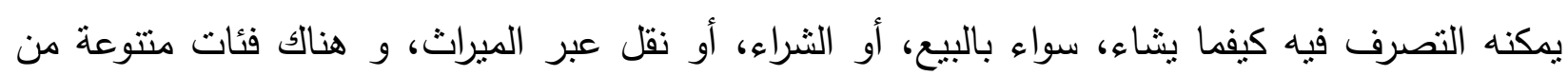

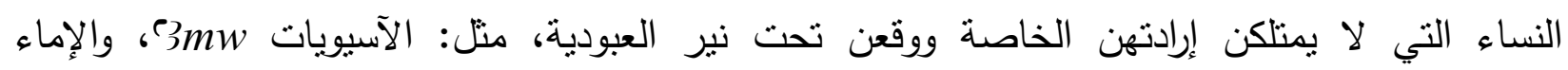

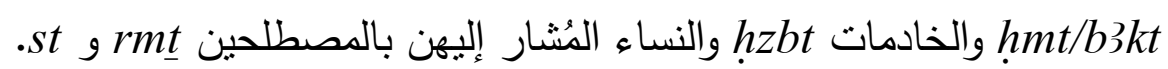




\section{ثبت المصادر والمراجع}

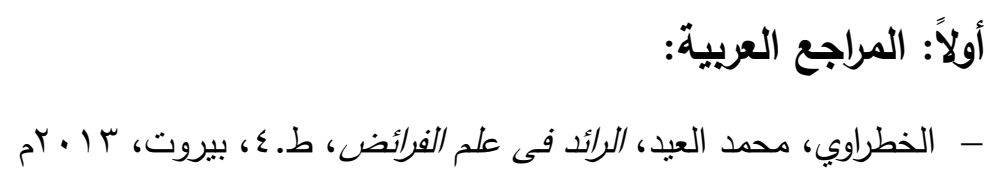

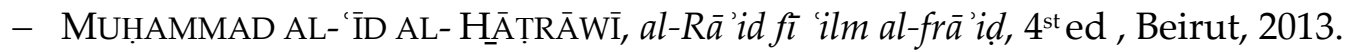

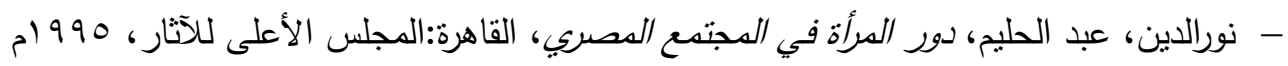

- 'ABD AL-ḤALĪM - NŪR AL-DīN, Dawr al-mar'a fì al-mūğgtama 'a al-mișrī, Cairo: al-Māğlis al-A 'āa li'l-Atāar, 1995 .

- شويدح، مؤمن، "أثر وسائل الاتصال الحديثة على الميراث المفقود في الفقه الإسلامي"، رسالة ماجستير غير منشورة،

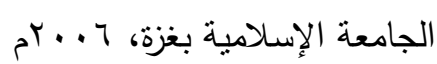

- MŪ'MIN ŠŪWĪDAḤ, «Atar wāsā'ilu al-Itiṣāl al-Ḥadīta 'alā al-mīrāt al-mafqūd fī al-Fīqh al' Islāmī̀, Master theses (Unpublished), The lslamic University of Ġāzā, 2006 .

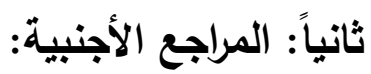

- ALLAM, S:.« Eine Abstandsurkunde aus der Zeit des Neuen Reiches» , JEA 53, 1967, 47-50.

- ................ Hieratische Ostraka und Papyri aus der Ramessidenzeit, Tübingen, 1973.

- ........... : «Quelques Aspects du Mariage dans l'Egypte Ancienne», JEA 67, 1981, 116-35.

- $\ldots \ldots \ldots \ldots . . . . . \ll$ Some Remarks on the Trial of Mose», JEA 75, 1989, 103-12.

- .................. Women as Owners of Immovables in Pharaonic Egypt, LESKO, B. S. (ed.), Women's

Earliest Records: from Ancient Egypt and Western Asia; Atlanta, 1989, 123-35.

- ......... : A New Look at the Adoption Papyrus (Reconsidered)» , JEA 76, 1990, 189-91.

- ........... : Egyptian Law Courts in Pharaonic and Hellenistic Times» , JEA 77, 1991, 109-27.

- ............ Papyrus Turin 2021Another Adoption Extraordinary, CANNUYER, KRUCHTEN, J.

(eds), Individu, Societe et Spiritualite. Melanges Théodoridès, Brusseles: Illustra, 1993, 23-28.

- ........... :« Ein Erbstreit um Sklaven (Papyrus BM 10568)» , Z ̈̈S 128, 2001, 89-96.

- ALLEN, J. , Middle Egyptian: An Introduction to the Language and Culture of Hieroglyphs, Cambridge University Press, 2000.

- BLACKMAN, A .: On the Position of Women in the Ancient Egyptian Hierarchy», JEA 7, 1921, 8-30.

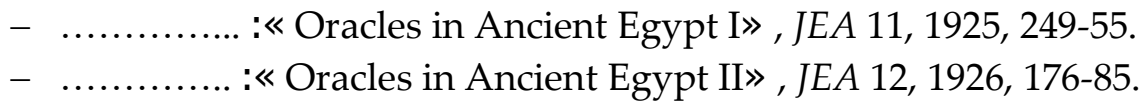

- BREASTED, J. H, Ancient Records of Egypt, I, Chicago, 1906.

- ..........., Ancient Records of Egypt, II, Chicago, 1906.

- ............, Ancient Records of Egypt, III, Chicago, 1906.

- CAMINOS, R, Late Egyptian Miscellanies, London, 1954.

- ......... : The Nitocris Adoption Stela», JEA 50, 1964, 71-101.

- ČERNÝ, J:.« Le Culte d'Aménophis ler chez les Ouvriers de la Nécropole Thébaine», BIFAO 27, 1928, 159-203.

: The Will of Naunakhte and the Related Documents» , JEA 31, 1945, $29-53$.

- ČERNÝ, J. \& GARDINER, A, Hieratic Ostraca, Oxford, 1957.

- ČERNÝ, J. \& PEET, :« A Marriage Settlement of the Twentieth Dynasty» , An Unpublished Document from Turin1, JEA 13.1, 1927, 30-39. 
- COLLIER, M. \& QUIRKE, S., The UCL Lahun Papyri: Religious, Literary, Legal, Mathematical and Medical, with a Chapter by ANNETTTE IMHAUSEN AND JIM RITTER, Oxford, 2004.

- - The UCL Lahun Papyri: Accounts, Oxford, 2006.

- DEMARÉE, R.J, A House is not a Home - What Exactly is a Hut?, DORN, A. \& HOFMAN, T. (eds), Living and Writing in Deir el-Medine: Socio-historical Embodiment of Deir el-Medina Texts, Basel: Schwabe Verlag, 2006.

- Donker VAn Heel, K., The legal Manual of Hermopolis: [P. Mattha], Text and Translation, Leiden, 1991.

- ERICHSEN, W, Auswahl Frühdemotischer Texte: zum Gebrauch im Akademischen Unterricht sowie zum Selbsstudium/zusammengestellt, Kopenhagen: Munksgaard, 1950.

- FAIRMAN, H:« Preliminary Report on the Excavations at Sesebi (Sudla) and 'Amārah West, Anglo- Egyptian Sudan, 1937-38» , JEA 24, 1938, 151-6.

- GABALLA, G. A., The Memphite Tomb-chapel of Mose, Warminster, 1977.

- GANLEY, A:.« The Legal Deeds of Transfer from 'Kahun, Part One'» , DE 55, 2003, 15-27.

- ............. : The Legal Deeds of Transfer from 'Kahun, Part Two'» , DE 56, 2003, 37-44.

- .............. :.«A Fresh Look at the Karnak Legal Stela» , DE 58, 2004, 57-67.

- GARDINER, A. H.:.« The Stela of Bilgai», Z $\ddot{A} S$ 50, 1912, 49-57.

- ......... :.«The Dakhleh Stela» , JEA 19, 1933, 19-30.

- ..............Adoption Extraordinary», JEA 26, 1941, 23-9.

- .......... , The Wilbour Papyrus, vol. II commentary, Oxford, 1948.

- .............. The Inscription of Mes: A Contribution to the Study of Egyptian Judicial Procedure, SETHE, K, (ed.), Untersuchungen zur Geschichte und Altertumskunde Ägyptens IV, Leipzig, 1964.

- GARDINER, A. \& SETHE, K., Egyptian Letters to the Dead mainly from the Old and Middle Kingdom, Egypt Exploration Society, 1928.

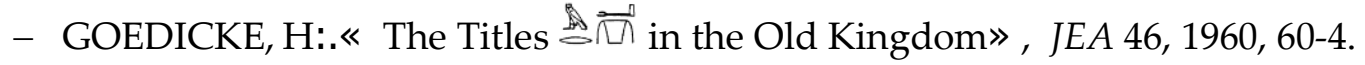

- ............... Die Laufbahn des MTn», MDAIK 21, 1966, 1-71.

- ............ Die Privaten Rechtsinschriften aus dem Alten Reich, Notring, 1970.

- ............ : Bilateral Business in the Old Kingdom», DE 5, 1986, 73-101.

- GRANDET, P., Catalogue des Ostraca Hiératiques non-Littéraires de Deîr el-Médînéh 8: Nos 706830. Documents de Fouilles de l'Institut Français d'Archéologie Orientale 39, Le Caire, 2000.

- ............., Catalogue des Ostraca Hiératiques non-Littéraires de Dê̂r el-Médînéh. Tome 12: Nos 10276-10405.Documents de Fouilles de l'Institut Français d'Archéologie Orientale 50, Le Caire, 2017.

- GUNN, B:.« A Middle Kingdom Stela from Edfu», ASAE 29, 1929, 5-14.

- ............. : «Notices of Recent Publications» , JEA 16, 1930, 147-55.

- JANSEN-WINKELN, K, Ägyptische Biographien der 22. und 23 ,. Dynastie., vol.3 , Ägypten und Altes Testament 8, Wiesbaden: Harrassowitz, 1985.

- JANSSEN, J. \& PESTMAN, P:« Burial and Inheritance in the Community of the Necropolis Workmen at Thebes (Pap. Bulaq X and O. Petrie 16)» , JESHO 11, 1968, 137-70.

- JASNOW, R, A Late Period Hieratic Wisdom Text (P. Prooklyn 47.218.135), Chicago, 1992.

- .........., Egypt: Old Kingdom and First Intermediate Period, Middle Kingdom and Second Intermediate Period, New Kingdom, Third Intermediate Period, WESTBROOK (ed.), A History of Ancient Near Eastern Law, vol.2, Brill, 2003, 93-140, 255-88, 289-359, 777- 818. 
- KITCHEN, K, Ramesside Inscriptions: Historical and Biographical I: Ramesses I, Sethos I, and Contemporaries. Oxford: Blackwell, 1975.

- ........., Ramesside Inscriptions: Historical and Biographical II, Oxford: Blackwell, 1979.

- ..........., Ramesside Inscriptions: Historical and Biographical III: Ramesses II and Contemporaries, Oxford, Blackwell, 1980.

- .........., Ramesside Inscriptions: Historical and Biographical VI: Ramesses IV to XI and Contemporaries, Oxford: Blackwell, 1983.

- .............., Ramesside Inscriptions: Translations I: Ramesses I, Sethos I, and Contemporaries, Oxford: Blackwell, 1993.

Ramesside Inscriptions: Translations II: Ramesses II: Royal Inscriptions, Oxford: Blackwell, 1996.

Ramesside Inscriptions: Translations III: Ramesses II and Contemporaries, Oxford: Blackwell, 2000.

- KRUCHTEN, J., Le Grand Texte Oraculaire de Djéhoutymose, Intendant du Domaine d'Amon sous le Pontificat de Pinedjem II, Brussels, 1986.

Un Oracle d' «Amenhotep du Village» sous Ramsès III. Ostracon Gardiner 103, DEMAREE, R.J. \& EGBERTS, A. (eds), Deir el-Madina in the Third Millennium, 2000, 209-16.

- $\quad$...........: « Derechef l'Ostracon DM 764», GM 198, 2004, 39-42.
- LEGRAIN, G .: «Deux Stèles Trouvées à Karnak en Février 1897 », ZÄS 35, 1897, 12-19.

- LOGAN, T:.« The Jmyt-pr Document: Form, Function, and Significance », JARCE 37, 2000, 49-73.

- LOPRIENO, A, Slavery and Servitude, in FROOD, E. \& WENDRICH, W. (eds), UCLA Encyclopedia of Egyptology, Los Angeles, 2012.

- LÜDDECKENS, E, Ägyptische Eheverträge. Ägyptologische Abhandlungen, I, 1960.

- MATTHA, G. \& HUGHES, G. R, The Demotic Legal Code of Hermopolis West, Cairo, 1975.

- MORET, A., .: “Donations et Fondations en Droit Egyptien”, In: Rec. trav. 29, 1907, 57-95.

- ........... Une Nouvelle Disposition Testamentaire de l'Ancien Empire Égyptien, Comptes Rendus des Séances de l'Acad.des Inscriptions \& Belles-Letters 58 , №.6), 1914, 53846.

- PERNIGOTTI, S., Due Papiri Demotici di età Persiana, BRESCIANI, E. (ed.), Scritti in Onore di Orsolina Montevecchi, Paris, 1981, 283-94.

- PESTMAN, P. W., Marriage and Matrimonial Property in Ancient Egypt: a Contribution to Establishing the Legal Position of the Woman, Leiden: Brill, 1961.

- ........... The Law of Succession in Ancient Egypt, Brill, 1969.

- ............ Les Papyrus Démotiques de Tsenhor (P. Tsenhor): Les Archives Privées d'une Femme Égyptienne du Temps de Darius Ier I: Textes. StudDem 4(1), Leuven: Peeters, 1994.

- .............. Les Papyrus Démotiques de Tsenhor (P. Tsenhor): Les Archives Privées d'une Femme Égyptienne du Temps de Darius Ier: II: Paléographie et planches. Studia Demotica 4(2) Leuven: Peeters, 1994.

- RITNER, R. K., The Libyan Anarchy: Inscription from Egypt's Third Intermediate Period, Atlanta, 2009.

- SCHENKE, H., Die Orakel im Alten Ägypten, P.hD Thesis , Humboldt-Universität zu Berlin, 1960.

Die Orakel im Alten Ägypten., WZHU Gesellschaftswissen-schaftliche Reihe 10 (1) 1961, 124-5. 
- SCHENKEL, W., Die Bewässerunggsrevolution im Alten Ägypten, Mainz/Rhein, 1978.

- SETHE, K., Ein Prozeßurteil aus dem Alten Reich, Zeitschrift für Ägyptische Sprache und Altertumskunde 61, 1926, 67 - 79.

Urkunden des Alten Reiches (Urk. I). Urkunden des Aegyptischen Altertums, Leipzig: Hinrichs, 1933.

, Urkunden der 18. Dynastie (Urk. IV), completed by WOLFGANG HeLCK). Urkunden des Aegyptischen Altertums IV. Leipzig: Hinrichs, 1958.

- SPALINGER, A., The Will of Senimose, JUNGE (ed.), Studien Westendorf, I, 631-51.

- .........: Dated Texts of the Old Kingdom», SAK 21, 1994, 275-319.

- THÉODORIDÈS, A.: « Le "Procès" dans la Stèle Juridique de Karnak», RIDA 4, 1957, 33- 52

- ............. : «L'Acte de Sounet (vente) dans la Stele Juridique de Karnak», RIDA 6. 1959, 107-30.

- .............. : La Stèle Juridique d'Amarah», RIDA 11, 1964, 45-80.

- ................ :Le Papyrus des Adoptions», RIDA 12, 1965, 79-142.

- ............. : A Propose de la Loi dans l'Egypte Pharaonique», RIDA 14, 1967, 107-52.

- .............. : «Procès Relatif á une Vente qui Devait être Acquittée par la Livraison d'un Travail Servile (Papyrus Berlin 9785)», RIDA 15, 1968, 39-104.

_ ....... : .«Les Ouvriers «Magistrats» en Égypte á l'Epoque Ramesside», RIDA 16, 1969, 103-88. "Le Testament dans l'Égypte Ancienne", RIDA 17, 1970, 117-216.

- ............, The Concept of Law in Ancient Egypt, HARRIS J. R (ed.), The Legacy of Egypt, Oxford: Clarendon Press, 1971, 291-322.

- TOIVARI-VIITALA, J. :«O. DeM 764: A Note Concerning Property Rights», GM 195, 2003, 87-96.

- VERSTEEG, R., Law in Ancient Egyptian Fiction, 24 Ga. J.Int'I\&Comp.L. 37, 1994.

- ............, Law in Ancient Egypt, Durham, North Carolina, 2002.

- WATTERSON, B., Women in Ancient Egypt, New York, 1991.

- WILKINSON, A. H., Early Dynastic Egypt, London/New York, 2001.

- WILLEMS, H.:« A Description of Egyptian kinship Terminology of the Middle Kingdom c. 2000-1650 BC», Bijdragen tot de taal-, land- en v139, Leiden, 1983,152-68. 